\title{
AVALIAÇÃO E QUANTIFICAÇÃO DE ATRIBUTOS DO SOLO ATRAVÉS DE DADOS RADIOMÉTRICOS OBTIDOS EM LABORATÓRIO
}

\author{
ALINE MARQUES GENÚ \\ Engenheiro Agrônomo
}

Orientador: Prof. Dr. JOSÉ ALEXANDRE M. DEMATTÊ

Dissertação apresentada à Escola Superior de Agricultura "Luiz de Queiroz", Universidade de São Paulo, para obtenção do título de Mestre em Agronomia, Área de Concentração: Solos e Nutrição de Plantas.

PIRACICABA

Estado de São Paulo - Brasil

Dezembro - 2002 


\section{Dados Internacionais de Catalogação na Publicação (CIP) DIVISÃO DE BIBLIOTECA E DOCUMENTAÇÃO - ESALQ/USP}

\section{Genú, Aline Marques}

Avaliação e quantificaçāo de atributos do solo através de dados radiométricos obtidos em laboratório / Aline Marques Genú. - - Piracicaba, 2002.

$64 \mathrm{p}$.

Dissertaçāo (mestrado) -. Escola Superior de Agricultura Luiz de Queiroz, 2002. Bibliografia.

1. Agricultura de precisāo 2. Laboratório 3. Propriedade físico-química do solo Quantificaçāo 4. Radiometria 1. Título

CDD 631.41 
Aos meus pais

Pedro Jaime e Maria de Fátima

\section{Aos meus irmãos}

Cristine, Fabrício e Adriane,

\section{OFEREÇO}

Ao meu avô

O Engenheiro Agrônomo Nady Bastos Genú

(in memoriam)

\section{DEDICO}




\section{AGRADECIMENTOS}

À Deus, pelo dom da vida.

Ao meu Orientador, Prof. Dr. José Alexandre M. Demattê pela confiança que depositou em mim e pela fundamental ajuda, sem a qual não seria possível terminar este trabalho.

À Coordenação de Aperfeiçoamento de Pessoal de Nível Superior, CAPES, pelo auxilio financeiro.

À Comissão de Pós-graduação do curso de Solos e Nutrição de Plantas da ESALQ/USP, pela oportunidade concedida, Prof. Dr. Álvaro Pires da Silva, Prof. Dr. Luis Reynaldo Ferracciú Alleoni, Prof. Dr. Pablo Vidal Torrado e Prof. Dr. Francisco Antônio Monteiro.

Ao Engenheiro Agrônomo Marcelo Corrêa Alves do Centro de Informática na Agricultura (CIAGRI) da ESALQ/USP pelo auxílio nas análises estatísticas.

À Faculdade de Agronomia e Medicina Veterinária (FAV) da Universidade de Brasília (UnB) pela minha formação acadêmica.

Aos meus "irmãos" Peterson, Caio, Rogério e Carlos pela ajuda e companheirismo.

Aos estagiários do Laboratório de Sensoriamento Remoto Conrado, João Paulo, Flávia, Maria Carolina e André pelo auxilio na obtenção dos dados radiométricos.

Aos amigos do curso de pós-graduação Márcio, Gilmar, Tiago, Ricardo e, em especial, a Gláucia e Karina pela ajuda e amizade.

À todos os funcionários do Departamento de Solos e Nutrição de Plantas, pela amizade e ajuda dispensada.

A todos aqueles que, de alguma forma, me ajudaram neste trabalho. 


\section{SUMÁRIO}

Página

RESUMO ….................................................................................... vii

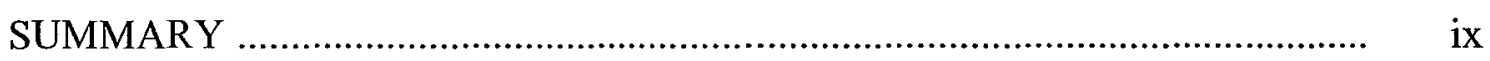

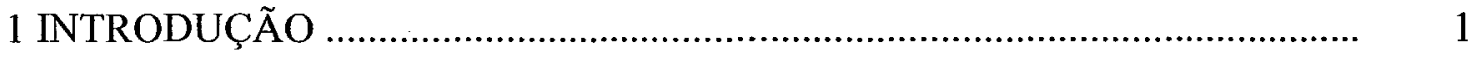

2 REVISÃO DE LITERATURA …….......................................................

2.1 Caracterização de solos através de sua resposta espectral ................................ 3

2.2 Relação entre dados espectrais e atributos dos solos ....................................... 5

2.3 Predição dos atributos dos solos através da sua resposta espectral ................ 8

3 ANÁLISE ESPECTRAL (450-2500 nm) DE SOLOS DA REGIÃO DE MOGI-GUAÇU, SP ......................................................................... 10

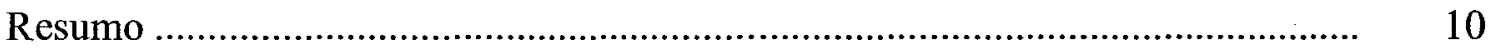

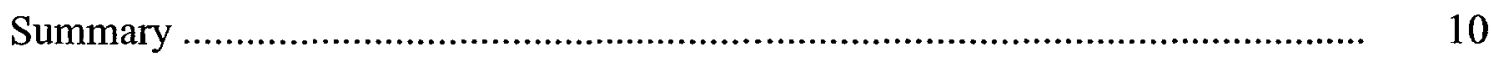

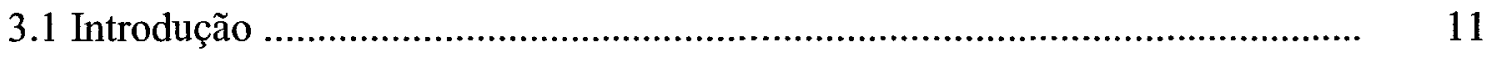

3.2 Material e Métodos ............................................................................... 12

3.3 Resultados e Discussão ........................................................................... 13

3.3.1 Comportamento espectral dos solos ...................................................... 14

3.3.2 Feições de absorção das curvas espectrais ................................................... 16

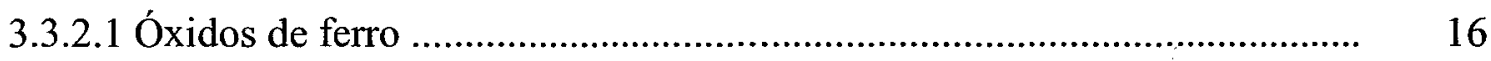

3.3.2.2 Minerais 2:1, caulinita e gibbsita .......................................................... 18

3.4 Conclusões ............................................................................................... 19

4 DETERMINAÇÃO DE TEORES DE ATRIBUTOS DO SOLO POR MEIO

DA ENERGIA ELETROMAGNÉTICA REFLETIDA ........................................ 25

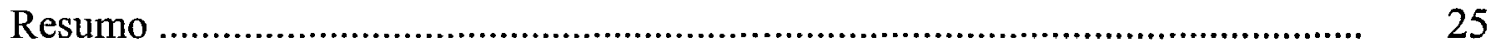




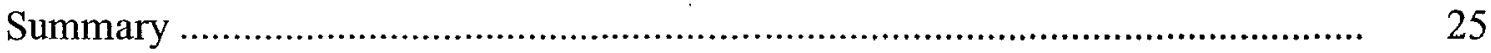

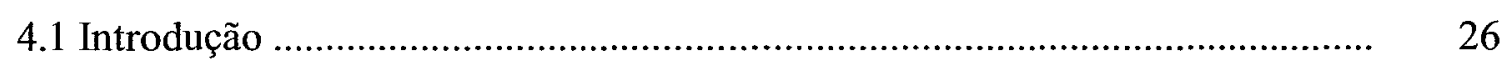

4.2 Material e Métodos ................................................................................... 27

4.2.1 Caracterização dos solos e áreas de estudo .................................................. 27

4.2.2 Análises químicas e granulométrica ………………………................... 28

4.2.3 Obtenção dos dados radiométricos ............................................................. 28

4.2.4 Análise estatística ................................................................................. 29

4.3 Resultados e Discussão ............................................................................ 30

4.3.1 Equações de regressão múltipla para estimativa de atributos físicos $\mathrm{e}$ mineralógicos ........................................................................................ 30

4.3.2 Equações de regressão múltipla para estimativa de atributos químicos ....... $\quad 32$

4.3.3 Avaliação dos valores determinados em laboratório com os estimados através das equações de regressão ...................................................................... 33

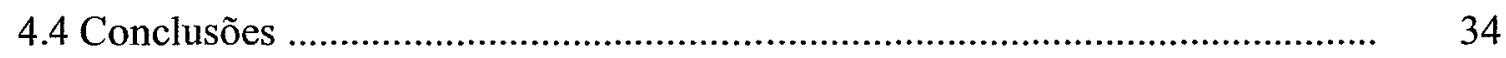

5 QUANTIFICAÇÃO DE ATRIBUTOS QUÍMICOS DE SOLOS ATRAVÉS

DE DADOS RADIOMÉTRICOS COM VISTAS À AGRICULTURA DE PRECISÃO ....................................................................................... 40

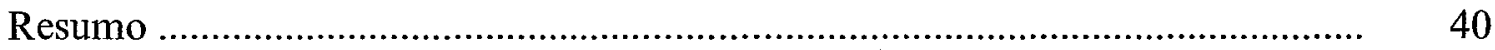

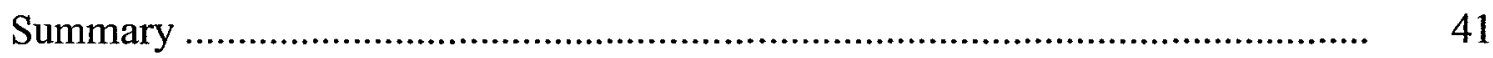

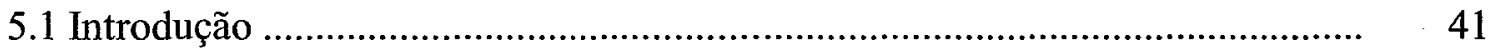

5.2 Material e Métodos .............................................................................. 43

5.2.1 Caracterização dos solos e área de estudo .................................................. 43

5.2.2 Obtenção dos dados radiométricos ............................................................... 43

5.2.3 Análise estatística ................................................................................... 44

5.3 Resultados e Discussão ...........................................................................

5.3.1 Equações de regressão múltipla ............................................................... 45

5.3.2 Necessidade de calagem ..................................................................... 48

5.4 Conclusões ......................................................................................... 50

6 CONCLUSÕES GERAIS ................................................................... 54

REFERÊNCIAS BIBLIOGRÁFICAS ........................................................ 55 


\title{
AVALIAÇÃO E QUANTIFICAÇÃO DE ATRIBUTOS DO SOLO ATRAVÉS DE DADOS RADIOMÉTRICOS OBTIDOS EM LABORATÓRIO
}

\author{
Autora: ALINE MARQUES GENÚ \\ Orientador: Prof. Dr. JOSÉ ALEXANDRE M. DEMATTÊ
}

\section{RESUMO}

Com a implantação da Agricultura de Precisão, o conhecimento detalhado da distribuição espacial dos solos e principalmente de seus atributos torna-se essencial. Neste sentido, o sensoriamento remoto vêm se mostrando bastante eficaz pois, em menos tempo e com menor custo, consegue-se obter informações sobre a variabilidade espacial dos solos e de seus atributos químicos, físicos e mineralógicos nos diferentes níveis de aquisição de dados. Neste sentido, este trabalho tem por objetivos avaliar quais fatores mais influenciam o comportamento espectral dos solos e correlacioná-los com seus atributos físicos, químicos e mineralógicos. Além disso, este trabalho visa estimar estes atributos a partir de equações de regressão múltipla utilizando-se um grande número de amostras de diferentes localidades e quantificar os atributos químicos de uma área específica. Para tal, dados radiométricos foram obtidos através de sensor em laboratório na faixa de $450-2500 \mathrm{~nm}$, para amostras de solos coletadas de diferentes municípios dos Estados de São Paulo, Paraná e Minas Gerais. Os dados radiométricos permitiram identificar a composição mineralógica de solos quanto à presença de óxidos de ferro, minerais 2:1, caulinita e gibbsita; determinar os teores de atributos físicos e mineralógicos dos solos a partir da metodologia utilizada; estimar atributos químicos 
pela energia eletromagnética refletida dos solos para uma região específica e modelos específicos assim como estimar a necessidade de calagem relacionando-se, portanto, com o manejo químico. 


\title{
EVALUATION AND QUANTIFICATION OF SOIL ATTRIBUTES THROUGH RADIOMETRIC DATA IN LABORATORY
}

\author{
Author: ALINE MARQUES GENÚ \\ Adviser: Prof. Dr. JOSÉ ALEXANDRE M. DEMATTÊ
}

\section{SUMMARY}

With the introduction of Precision Agriculture, the detailed knowledge of soil spatial distribution and its attributes is essential. In this sense, remote sensing is able to obtain information about soil variability and its chemical, physical and mineralogical attributes in different levels of data acquisition, in less time and smaller costs. In this way, the objective of this work was to evaluate which factors influence soil spectral behavior and correlate them with soils' physical, chemical and mineralogical attributes. Besides, this work also intends to esteem these attributes through multiple regression equations using a great number of samples of different places and to quantify the chemical attributes of a specific area. For this, radiometric data were obtained through laboratory sensor in a $450-2500 \mathrm{~nm}$ range, for soils samples collected from different areas of São Paulo, Paraná and Minas Gerais States. The radiometric data permited to evaluate the soils mineralogical compounds such as iron oxides, kaolinite, gibbsite and, 2:1 minerals; to determine the content of physical and mineralogical attributes by the adopted methodology; to estimate chemical attributes by eletromagnetic reflected energy with specific models for a region and to estimate lime recommendation related with chemical management. 


\section{INTRODUÇÃO}

Nos últimos anos, a área do sensoriamento remoto vem apresentando um grande desenvolvimento principalmente quanto a resolução dos sensores aerotransportados. Isto decorre, dentre outros motivos, da necessidade de monitorar com maior precisão a superfície terrestre. E, para que este objetivo seja alcançado, estudos sobre o comportamento dos alvos naturais em uma larga faixa de comprimento de onda é necessário.

O solo, devido a sua ocorrência, é um dos principais alvos a serem estudados, pois suas características podem influenciar a resposta espectral de outros objetos, como por exemplo a vegetação (Formaggio et al., 1996). Entretanto, o solo é um objeto dinâmico e sua resposta espectral está associada a sua composição e, como cada solo apresenta uma constituição própria, os diferentes tipos de solos apresentarão comportamentos também distintos.

Outra utilização do sensoriamento remoto está na agricultura de precisão, principalmente no que se refere a observação da variabilidade espacial dos atributos do solo, sendo o manejo da fertilidade do solo o objetivo principal (Thomasson et al,, 2001).

O estudo do solo por sensoriamento remoto normalmente envolve avaliações na faixa de 400-2500 nm (Epiphanio et al., 1992) pois, tem-se verificado que neste intervalo é possível obter informações sobre a constituição mineralógica do solo e também predizer seus atributos principalmente, quando se utiliza a análise multivariada como ferramenta auxiliar na analise dos dados (Leone \& Sommer, 2000).

Desta forma, o presente trabalho pretende avaliar a resposta espectral de solos e relacioná-la aos seus atributos químicos, físicos e mineralógicos, e gerar equações de 
regressão múltipla que possam estimar estes atributos. Espera-se que as diferentes características dos solos alterem a energia eletromagnética refletida, permitindo sua identificação e quantificação. 


\section{REVISÃO DE LITERATURA}

\subsection{Caracterização de solos através de sua resposta espectral}

Sensoriamento remoto é a ciência e a arte de se obter informações sobre um objeto, área ou fenômeno, através de análises dos dados adquiridos sem que o sensor entre em contato com o objeto, área ou fenômeno em estudo (Lillesand \& Kiefer, 2000) e, a medida dos valores de reflectância de um corpo ou alvo ao longo do espectro eletromagnético é definida como o seu comportamento espectral (Sabins Jr., 1987).

A reflectância do solo é uma propriedade cumulativa, derivada do comportamento espectral combinado de seus componentes como o tamanho de partícula, estrutura do solo, rugosidade superficial, umidade, conteúdo de matéria orgânica e mineralogia (Stoner \& Baumgardner, 1981). De acordo com Epiphanio et al. (1992), a reflectância também é influenciada pelo arranjamento das partículas, presença de água no solo e textura.

A correlação entre os constituintes do solo como matéria orgânica (Henderson et al., 1992), minerais silicatados (Hunt \& Salisbury, 1970) e óxidos de ferro (Kosmas et al., 1984) e suas respostas espectrais vêm sendo observadas.

Condit (1970) observou que os solos podem apresentar três Tipos de curvas espectrais, posteriormente Stoner \& Baumgardner (1981) incorporaram mais 2 Tipos. Os 5 Tipos básicos de curvas para solos são:

Tipo 1: exibem preferencialmente baixa reflectância, com uma declividade aumentando suavemente, o que thes imprime um formato côncavo característico, desde $320 \mathrm{~nm}$ até cerca de $1000 \mathrm{~nm}$. Segundo Stoner \& Baumgardner (1981), de 1000 a $1300 \mathrm{~nm}$ a 
declividade é praticamente constante para estes solos, uma característica não observada por Condit (1970), devido aos intervalo espectral limitado dos aparelhos usados.

Tipo 2: são caracterizadas por uma declividade geralmente decrescente até $600 \mathrm{~nm}$, seguida por um mergulho de 600 a $700 \mathrm{~nm}$. A declividade decrescendo acima de 0,75 $\mu \mathrm{m}$. O resultado é uma curva de formato convexo desde o visível até $1300 \mathrm{~nm}$.

Tipo 3: mostra uma declividade íngreme levemente decrescente em $0,60 \mu \mathrm{m}$, seguindose um leve mergulho de 620 a $740 \mathrm{~nm}$, com a declividade decrescendo até quase zero ou mesmo tornando-se negativa de 760 a $880 \mathrm{~nm}$, a declividade cresce com o aumento dos comprimentos de onda.

Tipo 4: essas curvas exibem uma declividade decrescente desde 880 até $1000 \mathrm{~nm}$, com a declividade decrescendo até zero, e tornando-se negativa de 1000 a $1300 \mathrm{~nm}$.

Tipo 5: essas curvas apresentam uma declividade decrescente até zero quando passa a negativa de 750 a $1300 \mathrm{~nm}$.

Em geral, a curva Tipo 1 apresenta um alto teor de matéria orgânica ( $>2 \%$ ), o que diminui sua reflectância, e com textura moderada a fina podendo os solos Podzolizados e os Cambissolos representarem este Tipo (Moraes, 1996). Solos com curvas do Tipo 2, como os Latossolo Amarelo e a Areia Quartzosa, apresentam baixo teor de matéria orgânica e médio teor de ferro (1-4). Para o tipo 3 verifica-se conteúdos moderadamente altos de ferro livre, alto teor de matéria orgânica e textura moderadamente grosseira, sendo segundo Moraes (1996) exemplificados pelos Latossolo Una e o Latossolo Vermelho-Amarelo. O quarto Tipo foi observado em solos com altos conteúdos de matéria orgânica e ferro como o Latossolo Vermelho-Escuro e, para o Tipo 5 altos conteúdos de ferro e textura fina, com baixos teores de matéria orgânica são verificados como por exemplo o Latossolo Roxo (Stoner \& Baumgardner, 1981).

Demattê (1995), utilizando os tipos de curvas de acordo com Condit (1970) e Stoner \& Baumgardner (1981), consegui separar os solos estudados em dois grupos, os originados de rochas básicas com curvas do Tipo 3 e 4 para Brunizem Avermelhado e Tipo 5 para Latossolo Roxo e Terra Roxa Estruturada, e os solos originados de rochas ácidas com curvas do Tipo 3 . 
Para o Brasil, Formaggio et al. (1996) obtiveram quatro padrões de formas de curvas, testando em laboratório 109 amostras de superficie e subsuperfície, de 13 classes de solos. Estas curvas foram separadas pela forma e intensidade de reflectância influenciadas pelo teor de óxidos de ferro, teor de matéria orgânica e material de origem.

Outras técnicas estão sendo utilizadas juntamente com o sensoriamento remoto para discriminar os solos a partir de sua resposta espectral. Demattê (1995) utilizou equações discriminantes para estabelecer classes de solos derivados de rochas eruptivas básicas e ácidas utilizando como variáveis preditoras 13 bandas selecionadas dentro do espectro eletromagnético ótico. Os resultados obtidos foram bastante satisfatórios, podendo-se estabelecer classes de solos através das equações.

Além disso, a utilização da denominada "linha do solo" também tem se mostrado eficaz na avaliação dos solos (Galvão \& Vitorello, 1998). Segundo Huete (1989) e Baret et al. (1993), os dados de reflectância de um solo, sem a interferência da vegetação, quando relacionada às bandas 4 e 3 do TM, dispõem-se ao longo de uma linha imaginária a 45 graus do eixo.

\subsection{Relação entre dados espectrais e atributos dos solos}

Diversos trabalhos têm sido feitos para verificar as feições de absorção dos componentes do solo no seu comportamento espectral.

\section{a) Minerais de argila silicatados}

Dentre os minerais de argila de solos, grande parte dos estudos estão relacionados a caulinita e aos minerais 2:1, dentre eles o grupo das montmorilonitas. As feições de absorção pra tais minerais estão centradas em 1400 e $2200 \mathrm{~nm}$, devido as presença dos grupos $\mathrm{OH}^{-}$das estruturas destes minerais e de sua ligação com outros cátions como o alumínio (Clark et al., 1990). As montmorilonitas, como apresentam moléculas de água entre as camadas unitárias, mostram uma banda de absorção intensa 
em 1900 nm (Hunt \& Salisbury, 1970), o que se deve às vibrações de moléculas de água neste comprimento de onda.

Desta forma, solos cauliníticos apresentam banda de absorção fraca em $1900 \mathrm{~nm}$. No caso da maior presença de minerais 2:1, a intensidade das bandas de absorção em 1400 e em $1900 \mathrm{~nm}$ vai ser bem maior, como constatado por Demattê \& Garcia (1999a) trabalhando com Brunizem Avermelhado. Similarmente, Grove et al. (1992) verificaram que outros minerais do grupo 2:1 como a vermiculita também apresentam banda forte em $1900 \mathrm{~nm}$.

A coincidência da presença de feição de absorção em $2200 \mathrm{~nm}$ para estes dois minerais foi discutida por Hauff et al. (1990) e, posteriormente, por Kruse et al. (1991) em trabalhos que visavam a identificação da caulinita e da esmectita em materiais que continham a mistura destes minerais e, verificaram que a caulinita apresenta uma feição dupla em $2200 \mathrm{~nm}$ o que não ocorre para os minerais $2: 1$.

\section{b) Óxidos de ferro}

Goethita e hematita são os óxidos de ferro de maior ocorrência nos ambiente tropicais, a predominância de uma forma ou de outra deve-se a fatores pedoclimáticos (Kämp \& Curi, 2000).Estes minerais apresentam características distintas ao longo da curva espectral, responsável pela cor, avermelhada para hematita e parda amarelada e amarelada, para goethita.

Scherman \& Waite (1985) determinaram as posições das feições de absorção nas curvas espectrais em $530 \mathrm{~nm}$ e $480 \mathrm{~nm}$ para hematita e goethita, respectivamente. Posteriormente, Scheinost et al. (1998) verificaram que a banda de absorção da hematita ocorre na faixa de $521 \mathrm{~nm}$ a $565 \mathrm{~nm}$ e na goethita ocorre de $479 \mathrm{~nm}$ a $493 \mathrm{~nm}$.

Stoner \& Baumgardner (1981) concluíram que, por volta de 700 e de $900 \mathrm{~nm}$, podem ser vistas as bandas de absorção devidas à influência do $\mathrm{Fe}_{2} \mathrm{O}_{3}$. Em solos pobres em ferro, pode ser observada uma faixa mais estreita de absorção em $900 \mathrm{~nm}$.

Os minerais pesados e opacos, como a magnetita e a ilmenita, que são muito abundantes em solos derivados de rochas eruptivas básicas, alteram todo o espectro 
óptico reduzindo a reflectância (Hunt et al., 1971). As absorções responsáveis pela opacidade têm sido atribuídas à transferência de carga entre os íons de ferro e entre os íons de ferro e oxigênio (Streus \& Wood, 1979).

\section{c) Matéria Orgânica}

As variações na intensidade da reflectância, na curva espectral, se devem ao teor da matéria orgânica assim como à sua natureza. Um dos primeiros estudos sobre os efeitos da natureza da matéria orgânica na curva espectral foi feito por Obukhov \& Orlov (1964), que verificaram a baixa reflectância da curva espectral devida aos ácidos húmicos. Henderson et al. (1992) salientaram que tais efeitos se devem à grande variação molecular dos constituintes do ácido húmico, tais como os grupos fenólicos e seus produtos de oxidação, os aminoácidos e seus produtos de condensação. A natureza das relações entre a composição da matéria orgânica e a reflectância do solo não é ainda inteiramente entendida (Demattê et al., 1998a).

Os ácidos húmicos têm uma reflectância extremamente baixa $(<2 \%)$ em toda a curva espectral e os ácidos fúlvicos atingem uma reflectância máxima de $20 \%$ a $750 \mathrm{~nm}$ (Vinogradov, 1981).

Autores como Courault \& Girard (1988) verificaram que a remoção da matéria orgânica resultou num aumento na curva de reflectância em toda sua extensão, entre 400 e $2500 \mathrm{~nm}$, embora na faixa antes dos $1300 \mathrm{~nm}$ as diferenças sejam pequenas. Madeira Netto (1993) verificou que as alterações nas curvas espectrais em solos muito intemperizados após a remoção da matéria orgânica se deve a diversas combinações como no próprio teor de matéria orgânica, no teor de óxido de ferro, na presença ou não de minerais opacos.

Baumgardner et al. (1970) mostram que em quantidades superiores a $2 \%$, a matéria orgânica pode provocar um efeito de mascaramento na contribuição que os outros constituintes dão para a característica espectral do solo, na região refletiva do espectro eletromagnético. Entretanto, Epiphanio et al. (1992) determinaram um valor de 
2,6 \%, enquanto que Demattê (1995) chegou a observar que teores de até $2,9 \%$ não mascararam a contribuição de outros constituintes do solo.

\subsection{Predição dos atributos dos solos através da sua resposta espectral}

A estimativa de atributos a partir de sua resposta espectral tem sido verificada. Coleman \& Montgomery (1990) obtiveram equações através de regressão multivariada entre dados espectrais e propriedades físicas e químicas dos solos e, tais equações foram capazes de estimar as propriedades estudadas.

Coleman et al. (1991), trabalhando com oito solos do Alabama, obtiveram boas correlações entre os dados espectrais e as variáveis argila, silte, matéria orgânica e óxidos de ferro dos solos estudados.

Henderson et al. (1992) estudando a faixa espectral de 400 a $2500 \mathrm{~nm}$, concluíram que se pode prever teores de matéria orgânica em solos, porém, não a sua composição.

Ben-Dor \& Banin (1995a) obtiveram altos coeficientes de determinação para a estimativa de carbonatos, matéria orgânica, e argila. Enquanto Janik et al. (1998) obtiveram valores de $\mathrm{R}^{2}$ muito significativos para estimar atributos mineralógicos, químicos e físicos de solos da Austrália.

Demattê \& Garcia (1999a) estabeleceram equações de regressão múltipla para predição de diversos atributos de solos desenvolvidos sobre rochas eruptivas. Dentre os atributos analisados, as melhores correlações foram encontradas para os teores de ferro, argila, $\mathrm{Al}_{2} \mathrm{O}_{3}$, titânio, manganês e caulinita.

Demattê (1999) visando a estimativa de 25 atributos de solos de com argila de baixa atividade, no Estado de São Paulo, verificou que os atributos estruturais do solo como areia, argila, $\mathrm{Al}_{2} \mathrm{O}_{3}, \mathrm{TiO}_{2}, \mathrm{Fe}_{2} \mathrm{O}_{3}, \mathrm{MnO}_{2}$ e formas de ferro apresentaram altos coeficientes de determinação porém, os elementos trocáveis como Ca e $\mathrm{K}$ foram pouco confiáveis.

Nanni (2000) utilizando espectroradiômetro para a estimativa de atributos de solos através de sua resposta espectral verificou que $\mathrm{SiO}_{2}, \mathrm{TiO}_{2}$ e $\mathrm{Fe}_{2} \mathrm{O}_{3}$ apresentaram 
altos coeficientes de determinação enquanto que os de $\mathrm{V} \%$ e $\mathrm{m} \%$ foram baixos e pouco confráveis.

Chang et al. (2001) observaram ótimos resultados utilizando análise de componentes principais para 17 atributos do solo enquanto, Thomasson et al. (2001) verificaram resultados satisfatório para as bases trocáveis.

Fiorio (2002) estudando solos de São Paulo, conseguiu valores de $\mathrm{R}^{2}$ satisfatórios para atributos mineralógicos e, a partir de comparação entre valores estimados por equações geradas com dados radiométricos e valores determinados em laboratório de análise de solo, foi possível estimar estas propriedades. 


\section{ANÁLISE ESPECTRAL (450-2500 nm) DE SOLOS DA REGIÃo DE MOGI- GUAÇÚ, SP}

\section{Resumo}

Com o desenvolvimento das técnicas de sensoriamento remoto, o entendimento da resposta espectral dos solos com a finalidade de auxiliar no mapeamento e na estimativa dos atributos do solo torna-se necessária. Desta forma, este trabalho teve por objetivo analisar a resposta espectral de oito perfis de solos da região de Mogi-Guaçú, SP, obtida em laboratório e correlacioná-la com as características físicas, químicas e mineralógicas dos solos. Os solos foram amostrados por horizontes e os dados de reflectância foram obtidos em laboratório utilizando-se um espectroradiômetro (450$2500 \mathrm{~nm}$ ). Foi possível diferenciar a resposta espectral de cada solo e correlacioná-la com a textura, conteúdo de matéria orgânica e teor óxido de ferro. A análise da energia eletromagnética refletida permitiu avaliar a composição mineralógica dos solos com relação aos óxidos de ferro, caulinita, gibbsita e minerais 2:1. Tais resultados indicam que a técnica pode ser utilizada como auxílio no estudo e mapeamento dos solos.

\section{SPECTRAL ANALYSIS (450-2500 nm) OF SOILS FROM MOGI-GUAÇU, SP REGION}

Summary

With the development of remote sensing techniques, the understanding of soil spectral response with the purpose to assist soil mapping and estimating soil attributes 
becomes necessary. For this, the objective of this work was to analyse the spectral response of eight soil profiles from the region of Mogi-Guaçu, SP, obtained in laboratory and correlate them with soil physical, chemical and mineralogical characteristics. The soils were sampled in each horizon and radiometric data was obtained by a spectroradiometer in laboratory. It was possible to discriminate the spectral response of each soil and relate them with texture, organic matter and iron oxides content. The analysis of reflective electromagnetic energy permited to evaluate the soils mineralogical compounds like iron oxides, kaolinite, gibbsite and 2:1 minerals. These results indicate that this technique can be used as an auxiliary method in soil studies and mapping.

\subsection{Introdução}

Com o desenvolvimento de novos sensores orbitais e aerotransportados de resoluções cada vez melhores, informações mais detalhadas sobre o comportamento espectral dos alvos naturais são necessárias. O solo, devido sua ocorrência na superfície terrestre, contribui significativamente na resposta espectral de outros alvos como, por exemplo, a vegetação (Formaggio et al., 1996). Além disso, o sensoriamento remoto vem se mostrando uma ferramenta bastante útil no mapeamento e na estimativa de atributos de solos.

As variações que ocorrem na resposta espectral dos solos estão normalmente ligadas a fenômenos específicos de absorção dos elementos que o compõem possibilitando, desta forma, a identificação das características dos solos, tornando o sensoriamento remoto uma importante ferramenta para a análise dos solos nos diferentes níveis de aquisição de dados (Madeira Netto, 1996).

Muitos trabalhos na literatura internacional vêm sendo realizados com o intuito de determinar a relação entre atributos do solo e sua energia refletida como Hunt \& Salisbury (1970), Kosmas et al. (1984), Henderson et al. (1992) e Ben-Dor (2002), entretanto, poucos são os trabalhos relacionados ao comportamento espectral dos solos 
brasileiros, fato que têm interferência em diversos campos da ciência do solo como a pedologia (Demattê, 2002).

Portanto, o presente trabalho objetiva analisar a resposta espectral de 8 perfis de solos da região de Mogi-Guaçú, Estado de São Paulo, obtida em laboratório na faixa de 450 a $2500 \mathrm{~nm}$, correlacionado-a com as características físicas, químicas e mineralógicas dos solos visto que, o solo é um sistema complexo e sua resposta espectral está relacionada a combinação dos elementos que o compõem como minerais, matéria orgânica e solução do solo (Stoner et al., 1980). Como cada solo apresenta uma composição diferente, é de se esperar que cada um deles também possua uma resposta espectral distinta ou uma assinatura espectral.

\subsection{Material e Métodos}

A área localiza-se no Estado de São Paulo, na região de Mogi-Guaçú, nas coordenadas $22^{\circ} 21^{\prime} 50^{\prime \prime} \mathrm{S}$ e $46^{\circ} 56^{\prime} 35^{\prime \prime} \mathrm{W}$. O clima da região apresenta um período chuvoso de novembro a março e seco de julho e agosto. A litologia é representada pelo grupo Tubarão (Formações Itararé e Aquidauana), as rochas das duas formações deste grupo são sedimentos extremamente variados em textura, indo dos arenitos mais grosseiros passando por siltitos e folhelhos de natureza argilosa.

Oito perfis de solo foram descritos (Lemos \& Santos, 1996) e amostras dos horizontes foram coletadas. Como os solos apresentam horizontes diagnósticos distintos,

optou-se por denominar genericamente os horizontes de A, B e C sendo que a profundidade de coleta e o nome de cada horizontes estão descritos na Tabela 1. As amostras coletadas foram analisadas quimicamente para $\mathrm{pH}\left(\mathrm{CaCl}_{2}\right)$, teor de matéria orgânica, fósforo, potássio, magnésio, cálcio, alumínio e hidrogênio mais alumínio, segundo metodologia descrita em Raij et al. (1987) e determinados os teores de areia, silte e argila de acordo com Camargo et al. (1986).

Com o resultado das análises e a descrição dos solos, os perfis foram classificados de acordo com Embrapa (1999) como sendo: Perfil 1 - NEOSSOLO QUARTZARÊNICO Órtico típico (RQo), Perfil 2 - LATOSSOLO VERMELHO- 
AMARELO Distrófico típico (LVAd), Perfil 3 - LATOSSOLO VERMELHO Distroférrico típico (LVdf), Perfil 4 - ARGISSOLO VERMELHO-AMARELO Distrófico arênico (PVAd1), Perfil 5 - ARGISSOLO VERMELHO-AMARELO Distrófico típico (PVAd), Perfil 6 - ARGISSOLO VERMELHO-AMARELO Distrófico latossólico (PVAd2), Perfil 7 - GLEISSOLO MELÂNICO Distrófico (GMd), Perfil 8 CAMBISSOLO HÁPLICO Tb Distrófico (CXbd).

As amostras de terra encaminhadas para laboratório foram secas em estufa por 24 $\mathrm{h}$ à $45^{\circ} \mathrm{C}$, moídas e peneiradas (malha de $2 \mathrm{~mm}$ ) para a leitura de sua reflectância, que foi obtida utilizando-se o espectrorradiômetro Infra Red Intelligent Spectroradiometer (IRIS), com resolução de $2 \mathrm{~nm}$ entre 450 e $1100 \mathrm{~nm}$ e $4 \mathrm{~nm}$ entre 1100 e $2500 \mathrm{~nm}$. A geometria para aquisição dos dados foi àquela destacada por Demattê et al. (1998a).

As amostras foram acondicionadas em placas de petri com $9 \mathrm{~cm}$ de diâmetro e $1,5 \mathrm{~cm}$ de altura, localizada a $61 \mathrm{~cm}$ da fonte de iluminação (lâmpada halógena de 650 W com refletor parabólico e feixe não colimado) e $27 \mathrm{~cm}$ do sensor. A lâmpada foi colocada a um ângulo de $15^{\circ}$ ao nadir e a energia elétrica foi estabilizada por uma fonte de potência, evitando distúrbios de intensidade na iluminação. A reflectância bidirecional aqui utilizada foi definida de acordo com Nicodemus et al. (1977).

Os dados foram posteriormente calibrados e filtrados por software específico denominado Conviris (Steffen, 1997), para diminuição do ruídos e facilitar a interpretação das curvas espectrais

Os teores de $\mathrm{SiO}_{2}, \mathrm{Fe}_{2} \mathrm{O}_{3}$ e $\mathrm{TiO}_{2}$ foram obtidos a partir de equações de regressão múltipla geradas por Nanni \& Demattê (2001). As variáveis radiométricas (bandas e alturas) das equações foram substituídas pelos valores obtidos para os solos aqui estudados gerando os teores estimados de $\mathrm{SiO}_{2}, \mathrm{Fe}_{2} \mathrm{O}_{3}$ e $\mathrm{TiO}_{2}$. Posteriormente, os teores estimados foram comparados com análises químicas de outros perfis de mesma classificação, para verificar se os valores estavam compatíveis.

A segunda derivada foi realizada nas amostras do horizonte $\mathrm{B}$, para melhor observação das feições de absorção nas curvas espectrais, a partir da metodologia desenvolvida por Savitzky \& Golay (1964). 


\subsection{Resultados e Discussão}

\subsubsection{Comportamento espectral dos solos}

A análise das curvas espectrais dos perfis de solos estudados mostrou a existência de características distintas quanto à intensidade e presença das bandas de absorção (Figuras 1 e 2). O NEOSSOLO QUARTZARÊNICO (RQo) (Figura 1a) é um solo de textura arenosa, baixo teor de matéria orgânica (Tabela 1) e baixos teores de óxidos de ferro e titânio (Tabela 2) causando uma resposta espectral alta devido a mineralogia deste solo ser constituída basicamente de quartzo (Formaggio et al., 1996), entretanto, ocorrem também caulinita e gibbsita.

As diferenças encontradas nas respostas espectrais dos dois LATOSSOLOS está relacionada ao teor de argila (Tabela 1) e óxidos de ferro (Tabela 2) que aumentam do LVAd para o LVdf, proporcionando reflectância alta para LVAd (Figura 2a) e baixa para LVdf (Figura 1b). Outro fator importante relacionado a baixa intensidade de reflectância do LVdf, está na presença de minerais opacos como a magnetita que absorve energia em todo o espectro eletromagnético conforme verificado por Hunt et al. (1971) e ratificado por Demattê et al. (2001a) estudando solos. Por outro lado, ambos os solos apresentaram bandas de absorção pouco intensas em $1400 \mathrm{~nm}, 1900 \mathrm{~nm}$ e mais altas em $2200 \mathrm{~nm}$ demonstrando a mineralogia caulinítica destes solos, concordando com os resultados obtidos por Fiorio (2002) e Demattê (2002). Além disso, como estes solos são bastante homogêneos em todo o perfil, a forma da curva para os três horizontes é similar, havendo apenas um aumento da reflectância com o aumento da profundidade devido à diminuição do teor de matéria orgânica neste sentido, o que também foi observado por Galvão et al. (1997)

Os ARGISSOLOS, assim como os LATOSSOLOS, também apresentaram respostas distintas apesar de diferirem apenas no quarto nível categórico (subgrupos). $\mathrm{O}$ ARGISSOLO VERMELHO-AMARELO Distrófico arênico (PVAd1) (Figura 2b), devido sua textura arenosa (Tabela 1) possui uma resposta muito similar ao RQo e ao LVAd, assemelhando-se com o tipo $d$ de curvas espectrais descritos por Formaggio et al. 
(1996) o que concorda com Fiorio (2002) que também enquadrou as mesmas classes de solo neste padrão espectral. O horizonte A não apresenta, na faixa entre 450 e 900 nm, a feição de absorção relativa a presença dos óxidos de ferro além de ter uma intensidade mais baixa que os horizontes $\mathrm{B}$ e $\mathrm{C}$, estas características estão relacionadas a presença da matéria orgânica que mascara o efeito do ferro na resposta espectral do solo, assim como absorve energia diminuindo a sua intensidade (Mathews et al., 1973). A mineralogia é predominantemente caulinítica, como pode ser observado pela intensa banda de absorção em 2200 nm (Clark et al., 1990).

O ARGISSOLO VERMELHO-AMARELO Distrófico típico (PVAd) (Figura 2c) possui uma alta reflectância e as feições de absorção da água bastante intensas indicando a presença de mineralogia 2:1 neste solo, assim como a caulinita (2200 nm) e dos óxidos de ferro (450-600 nm). Assim como no PVAd1, o horizonte A apresenta um comportamento diferente dos demais. Demattê et al. (2001a) verificaram para dois ARGISSOLOS VERMELHO-AMARELOS Distróficos da região de Mogi-Mirim, que as bandas em $1400 \mathrm{~nm}\left(\mathrm{OH}^{-}\right.$e $\left.\mathrm{H}_{2} \mathrm{O}\right)$ assim como em $1900 \mathrm{~nm}\left(\mathrm{H}_{2} \mathrm{O}\right)$ foram mais pronunciadas, indicando a presença de mineralogia 2:1 o que foi confirmado por difratometria de raio-X.

O ARGISSOLO VERMELHO-AMARELO Distrófico latossólico (PVAd2) (Figura 2d) por sua vez é bastante semelhante ao LVdf. A região entre $450 \mathrm{~nm}$ e $550 \mathrm{~nm}$ apresenta a banda de absorção devido não aos altos teores de ferro mas aos óxidos de ferro, conforme verificado por Demattê \& Garcia (1999a).

O GLEISSOLO MELÂNICO (GMd) (Figura 2e) não apresenta a banda de absorção dos óxidos de ferro conforme verificado pelas derivadas (Figura 3a). A baixa intensidade de reflectância dos horizontes A e B está relacionada ao efeito da matéria orgânica. Mathews et al. (1973) comentam que a matéria orgânica diminui a intensidade de reflectância. Além disso, as feições da água (1400 e 1900 nm) mostraram-se intensas, assim como demonstrado por Demattê et al. (2001a) para um GLEISSOLO HÁPLICO caracterizando a presença de minerais 2:1 como vermiculita e micas. A banda de absorção da caulinita (2200 nm) também foi observada para este solo concordando com Demattê (1995). 
O CAMBISSOLO HÁPLICO (CXbd) por ser um solo menos intemperizado, apresenta uma resposta espectral mais alta concordando com as observações de Demattê \& Garcia (1999a), assim como as bandas de absorção da água mais intensas que a da caulinita, especialmente em $1900 \mathrm{~nm}$, indicando mineralogia 2:1 (Figura 2f). Demattê et al. (2000) verificaram que solos Litólicos apresentaram vermiculita e mica em sua composição, detectados pelos difratogramas de raio-X e, assim como o CXbd, também mostraram bandas de absorção intensas em $1400 \mathrm{~nm}, 1900 \mathrm{~nm}$ e $2200 \mathrm{~nm}$. O indicativo da relação entre intensidade de absorção e minerais $2: 1$ foi destacado por Hunt \& Salisbury (1970).

\subsubsection{Feições de absorção das curvas espectrais}

\subsubsection{1 Óxidos de ferro}

Goethita $(\mathrm{FeOOH})$ e hematita $\left(\mathrm{Fe}_{2} \mathrm{O}_{3}\right)$ são as formas mais freqüentes de ferro $\left(\mathrm{Fe}^{3+}\right)$ encontradas nos solos, resultantes da oxidação do ferro $\left(\mathrm{Fe}^{2+}\right)$ presente nos minerais primários durante o processo de formação do solo (Cornell \& Schwertmann, 1996).

A feição espectral do ferro, na faixa do visível ao infravermelho, resulta das transições eletrônicas do $\mathrm{Fe}^{3+}$ porém, os diferentes óxidos de ferro possuem respostas espectrais em comprimentos de onda distintos devido às diferenças estruturais dos minerais (Sherman \& Waite, 1985). A hematita e a goethita apresentam o $\mathrm{Fe}^{3+} \mathrm{em}$ coordenação octaedral com o oxigênio, entretanto, a goethita possui as ligações do $\mathrm{OH}^{-}$em posições diferentes do $\mathrm{O}^{2-}$ na hematita (Ben-Dor, 2002).

Os óxidos de ferro apresentam sua principal banda de absorção, que ocorre devido a transferência de carga metal-ligante $\left(\mathrm{Fe}^{3+} \rightarrow \mathrm{O}^{2-}\right)$, na faixa do ultravioleta, entretanto, Hunt et al. (1971) observaram que outra banda de menor intensidade para os óxidos de ferro ocorre na faixa de 450-600 nm (visível).

Os solos estudados apresentaram feição de absorção no comprimento de onda verificado para os óxidos de ferro porém, como esta é uma banda de baixa absorção e os diferentes óxidos apresentam respostas distintas, a determinação de qual tipo está presente 
no solo torna-se dificil desta forma. Para detecção da presença destes elementos realizou-se a derivada segunda do horizonte $\mathrm{B}$ dos solos estudados.

Observando-se as curvas da derivada segunda dos solos para óxidos de ferro (Figura 3a) verifica-se que as feições de absorção da goethita e hematita são distintas e ocorrem na faixa verificada por Scheinost et al. (1998) porém, Sherman \& Waite (1985) verificaram bandas em $530 \mathrm{~nm}$ e $480 \mathrm{~nm}$ para hematita e goethita, respectivamente, discordando do resultado aqui obtido.

Morris et al. (1985) também verificaram outras bandas de absorção para estes óxidos em outras faixas como 845 a $870 \mathrm{~nm}$ para hematita e, 900 a $930 \mathrm{~nm}$ e $650 \mathrm{~nm}$ para goethita, entretanto, não foi observada nenhuma feição nestes comprimentos de onda para os solos estudados. Isto pode estar relacionado com o fato destes autores terem utilizado amostras dos óxidos puros e não amostras de solos constituídas destes minerais.

Os óxidos, mesmo em baixas concentrações, têm um alto poder de pigmentação indo, desde solos vermelhos (hematíticos) com matiz $7.5 \mathrm{R}$ (segundo a notação Munsell) até $2.5 \mathrm{Y}$ onde a goethita é o óxido de ferro exclusivo e, os matizes intermediários de cor são o resultado da mistura destes minerais (Barrón et al., 2000). Logo, a cor é determinada pela distribuição e tipo de óxidos dentro de um perfil e ajuda a explicar a gênese do solo, além de ser uma característica utilizada em vários sistemas de classificação de solos (Kämpf \& Curi, 2000). Na classificação brasileira (Embrapa, 1999), a cor aparece no segundo nível categórico (subordem).

A relação da cor dos solos com a presença de óxidos de ferro, pode ser observada nos solos estudados (Figura 3a). Os solos vermelho-amarelos (LVAd, PVAd, PVAd1 e PVAd2) apresentam as bandas de absorção tanto da hematita quanto da goethita porém, com diferenças quando a intensidade da resposta espectral devido a textura e mineralogia apresentada por cada um deles.

Solos com matizes mais vermelhos, como o PVAd1, mostraram maior intensidade na faixa da hematita (Tabela 1, Figura 3a), enquanto o LVd possui apenas a feição da hematita por ser um solo de matiz vermelha (Tabela 1). 
O GMd não apresenta nenhuma feição para os óxidos devido ao alto teor de matéria orgânica que mascara os óxidos ou a inexistência destas formas de ferro em sua mineralogia.

Scheinost \& Schwertmann (1999) determinaram que a matiz de solos hematíticos é próxima da matiz do mineral puro sendo o mesmo verdadeiro pra goethita, confirmando a relação entre a cor e a presença dos óxidos de ferro no solo, ratificando os resultados aqui verificados. Por outro lado, o teor de ferro (Tabela 2) não apresenta relação com a matiz Munsell (Tabela 1), o que concorda com as observações de Kämpf \& Schwertmann (1983). Ou seja, o teor de ferro total, conforme estabelecido na Tabela 2, não implica na presença de óxidos de ferro. Isso faz com que uma amostra de terra possa apresentar alto teor de $\mathrm{Fe}_{2} \mathrm{O}_{3}$ e não apresente a concavidade espectral. $\mathrm{O}$ efeito da concavidade está intimamente relacionada com os óxidos cristalinos, que por sua vez relaciona-se com a cor dos solos.

\subsubsection{Minerais 2:1, caulinita e gibbsita}

Os solos avaliados apresentaram bandas de absorção em três comprimentos de onda específicos na faixa do infravermelho: 1400, 1900 e $2200 \mathrm{~nm}$. Basicamente, estas feições espectrais estão associados a "overtones" (transição de um modo vibracional de um estado de energia para outro nível de energia acima ou abaixo do original) e combinações (freqüências associadas a mais de um modo vibracional) de vibrações fundamentais do grupo $\mathrm{OH}^{-}$e da água (Ben-Dor et al., 1999; Chabrillat et al., 2002).

A hidroxila está presente na eștrutura dos minerais e possui apenas uma vibração ativa no infravermelho, situada em torno de $2750 \mathrm{~nm}$, porém, com um "overtone" próximo a $1400 \mathrm{~nm}$ (Clark et al., 1990), além disso, a combinação deste grupo com outros elementos como, por exemplo o $\mathrm{Al}$ e o $\mathrm{Mg}$, produz feições de absorção próximas de $2200 \mathrm{~nm}$ e $2300 \mathrm{~nm}$ e são diagnósticas dos minerais de argila (Chabrillat et al., 2002).

Os minerais 2:1, além das bandas em 1400 e $2200 \mathrm{~nm}$ também apresentam uma feição intensa em $1900 \mathrm{~nm}$ pela presença da água entre as lâminas do mineral (Frost et al., 2001). Tal fato demonstra que os solos PVAd e CXbd aqui apresentados possuem mineralogia 2:1 (Figuras 2c, 2f, 3b). Por outro lado, os mesmos solos também 
apresentam uma feição dupla em $2200 \mathrm{~nm}$ causada pela ligação Al-OH caracterizando a existência da caulinita. Este resultado está de acordo com o obtido por Demattê et al. (2001a) que verificaram a presença de minerais 2:1 e caulinita simultaneamente em Argissolos e Cambissolos de Mogi-Mirim através de difratometria de raio-X.

Da mesma forma, verificou-se para os demais perfis de solos a presença de caulinita, devido às feições em 1400 e $2200 \mathrm{~nm}$ (Figura 3c). Entretanto, uma banda de pequena intensidade em $1900 \mathrm{~nm}$ também foi observada para estes solos mas, de acordo com Clark et al. (1990) isto está relacionado com a presença de água na amostra e não com a existência de minerais $2: 1$.

Outro mineral muito encontrado nos solos tropicais é a gibbsita e, segundo verificado por Madeira Netto (1996) apresenta feição espectral em $2265 \mathrm{~nm}$ devido a vibração do $\mathrm{OH}^{-}$combinado com o alumínio. Nos solos estudados, com exceção do PVAd (Figura 3c), todos apresentaram este mineral. Resultado semelhante foi obtido por Demattê et al. (2000) no qual um Podzólico Vermelho Escuro de Piracicaba, não apresentou gibbsita na sua mineralogia.

\subsection{Conclusões}

1- A radiometria dos solos permitiu identificar a composição mineralógica dos solos com relação à presença de óxidos de ferro, minerais 2:1, caulinita e gibbsita.

2- Granulometria, teor de óxidos de ferro, matéria orgânica e composição mineralógica são os principais fatores que influenciam as feições de absorção e intensidade de reflectância.

3- Os óxidos de ferro, hematita e goethita, apresentam respostas espectrais em comprimentos de onda distintos devido às suas características estruturais específicas, e estão intimamente ligados a cor do solo. 


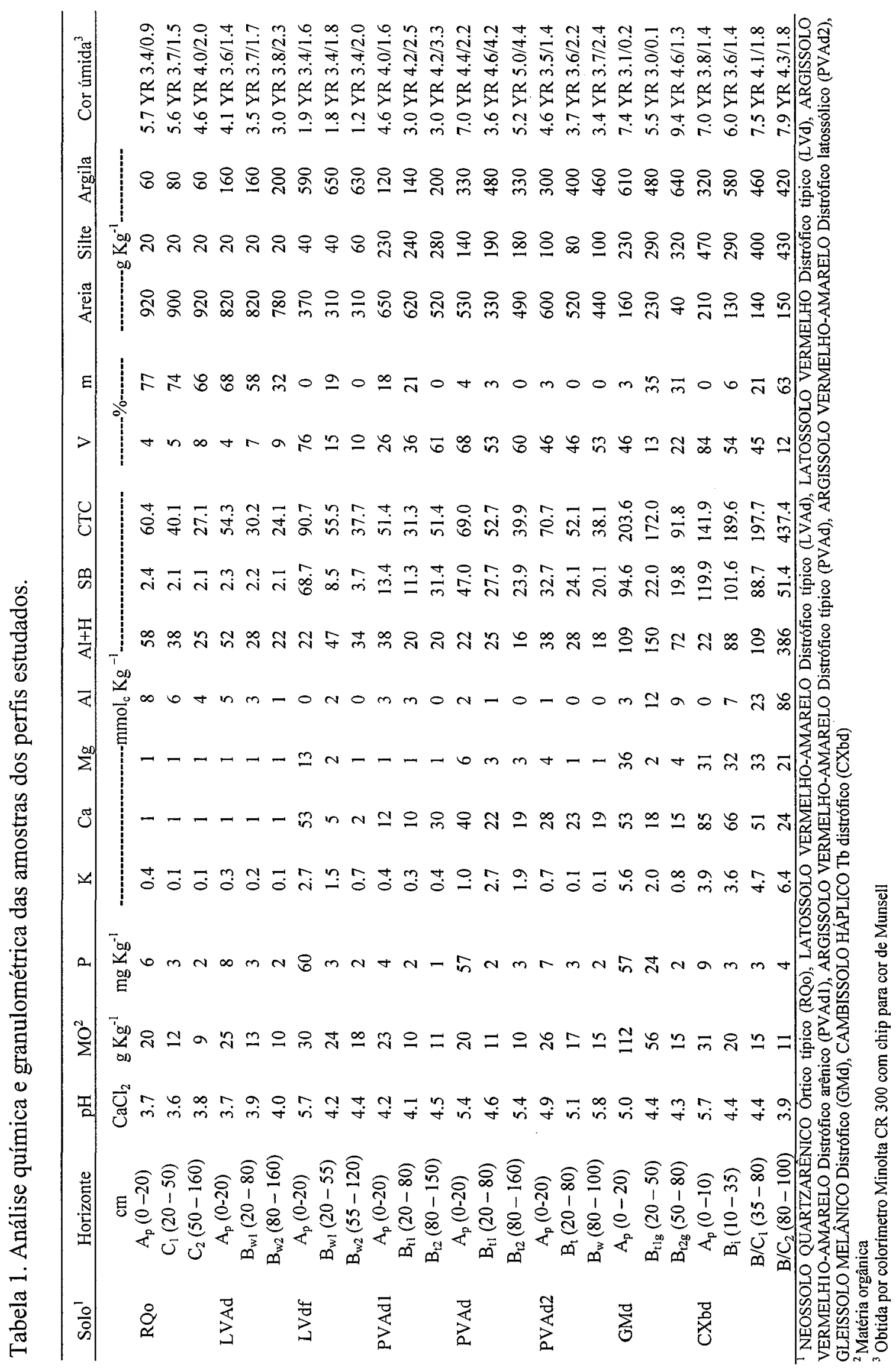


Tabela 2. Teores estimados de $\mathrm{SiO}_{2}, \mathrm{Fe}_{2} \mathrm{O}_{3}$ e $\mathrm{TiO}_{2}$ de acordo com a metodologia desenvolvida por Nanni \& Demattê (2001).

\begin{tabular}{|c|c|c|c|c|}
\hline Solo ${ }^{1}$ & Horizonte & $\mathrm{SiO}_{2}$ & $\mathrm{Fe}_{2} \mathrm{O}_{3}$ & $\mathrm{TiO}_{2}$ \\
\hline & 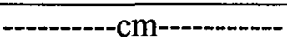 & - & $-\mathrm{g} \mathrm{Kg}^{-1}$ & \\
\hline \multirow{4}{*}{ RQo } & $A_{p}(0-20)$ & 2,77 & 42,40 & 11,69 \\
\hline & $C_{1}(20-50)$ & 2,84 & 35,33 & 5,57 \\
\hline & $C_{2}(50-160)$ & 2,82 & 34,48 & 5,44 \\
\hline & $A_{p}(0-20)$ & 2,81 & 31,87 & 6,00 \\
\hline \multirow[t]{3}{*}{ LVAd } & $\mathrm{B}_{\mathrm{w} 1}(20-80)$ & 2,66 & 27,47 & 3,91 \\
\hline & $\mathrm{B}_{\mathrm{w} 2}(80-160)$ & 2,73 & 29,88 & 4,23 \\
\hline & $A_{p}(0-20)$ & 3,19 & 168,28 & 27,33 \\
\hline \multirow[t]{3}{*}{ LVdf } & $B_{w 1}(20-55)$ & 3,30 & 223,07 & 29,56 \\
\hline & $\mathrm{B}_{\mathrm{w} 2}(55-120)$ & 3,31 & 201,51 & 24,58 \\
\hline & $A_{p}(0-20)$ & 2,71 & 16,72 & 8,16 \\
\hline \multirow[t]{3}{*}{ PVAdl } & $B_{t 1}(20-80)$ & 2,92 & 12,41 & 4,91 \\
\hline & $B_{t 2}(80-150)$ & 3,26 & 32,69 & 11,03 \\
\hline & $A_{p}(0-20)$ & 3,11 & 10,77 & 0,92 \\
\hline \multirow[t]{3}{*}{ PVAd } & $B_{t 1}(20-80)$ & 3,89 & 72,27 & 2,40 \\
\hline & $B_{t 2}(80-160)$ & 3,87 & 46,40 & 1,72 \\
\hline & $A_{p}(0-20)$ & 3,22 & 114,96 & 25,46 \\
\hline \multirow[t]{3}{*}{ PVAd2 } & $B_{t}(20-80)$ & 3,35 & 187,67 & 32,56 \\
\hline & $B_{w}(80-100)$ & 3,45 & 227,74 & 33,19 \\
\hline & $A_{p}(0-20)$ & 3,47 & 132,70 & 23,19 \\
\hline \multirow[t]{3}{*}{ GMd } & $\mathrm{B}_{\mathrm{t} \lg }(20-50)$ & 3,39 & 91,20 & 20,44 \\
\hline & $\mathrm{B}_{\mathrm{t} 2 \mathrm{~g}}(50-80)$ & 3,55 & 10,00 & 0,42 \\
\hline & $A_{p}(0-10)$ & 5,21 & 36,04 & 65,38 \\
\hline \multirow{3}{*}{ CXbd } & $B_{i}(10-35)$ & 6,52 & 32,95 & 253,06 \\
\hline & $\mathrm{B} / \mathrm{C}_{1}(35-80)$ & 6,88 & 15,13 & 193,02 \\
\hline & $B / C_{2}(80-100)$ & 6,17 & 31,86 & 111,25 \\
\hline
\end{tabular}

T NEOSSOLO QUARTZARÊNICO Órtico típico (RQo), LATOSSOLO VERMELHO-AMARELO Distrófico típico (LVAd), LATOSSOLO VERMELHO Distroférico típico (LVdf), ARGISSOLO VERMELHO-AMARELO Distrófico arênico (PVAdl), ARGISSOLO VERMELHO-AMARELO Distrófico típico (PVAd), ARGISSOLO VERMELHO-AMARELO Distrófico latossólico (PVAd2), GLEISSOLO MELÂNICO Distrófico (GMd), CAMBISSOLO HÁPLICO Tb distrófico (CXbd) 

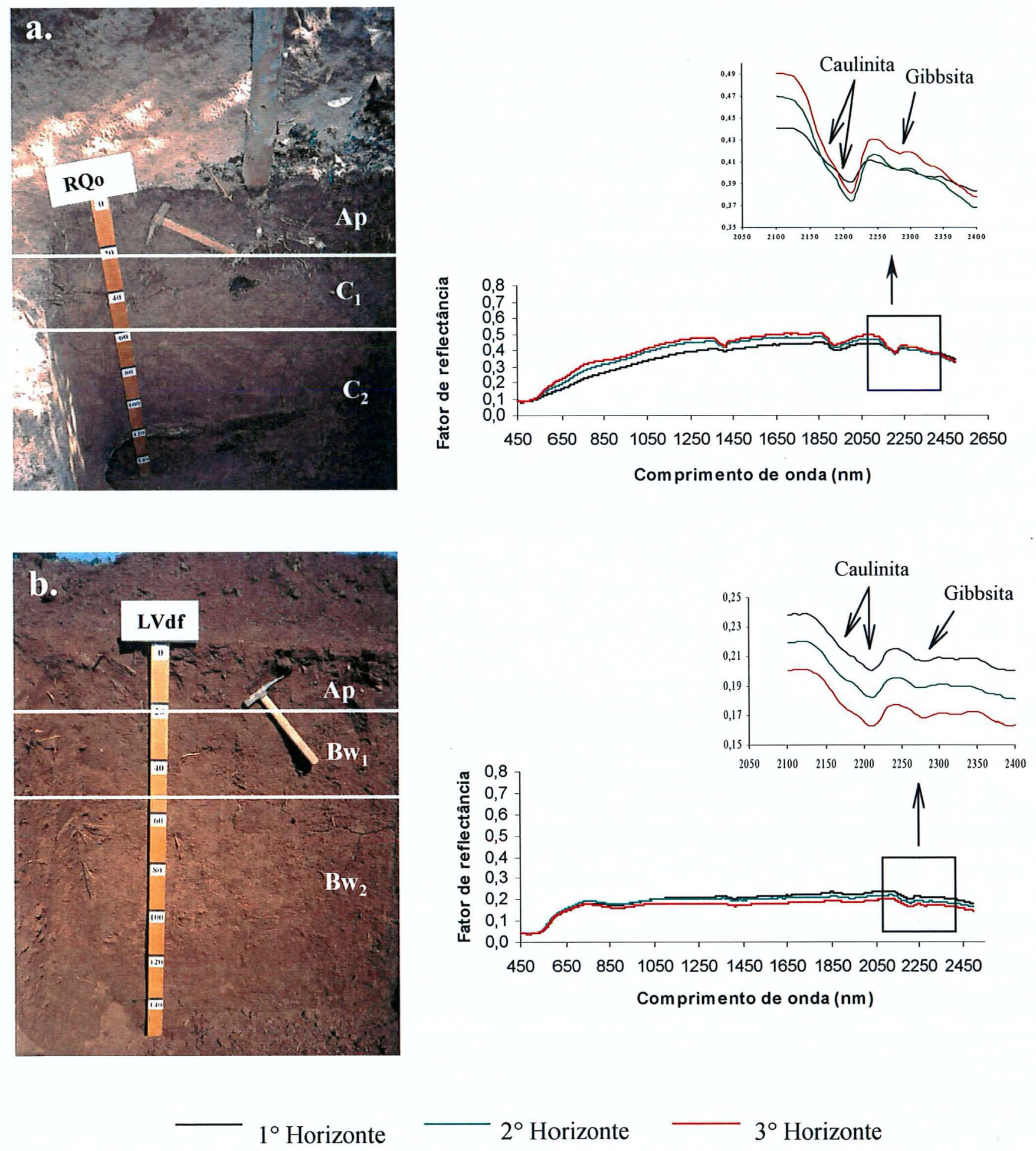

$2^{\circ}$ Horizonte

$3^{\circ}$ Horizonte

Figura 1 - Perfis de solos e suas respectivas curvas espectrais: a. NEOSSOLO QUARTZARÊNICO Órtico típico (RQo) e b. LATOSSOLO VERMELHO Distroférrico típico (LVdf). 


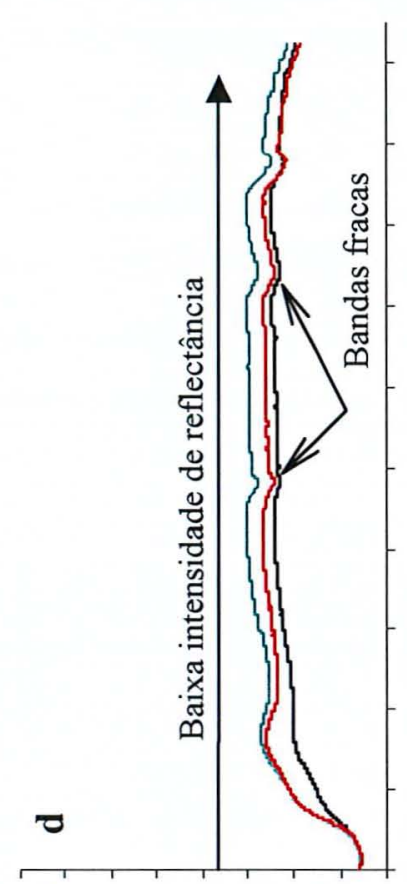

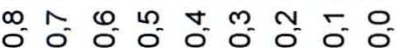

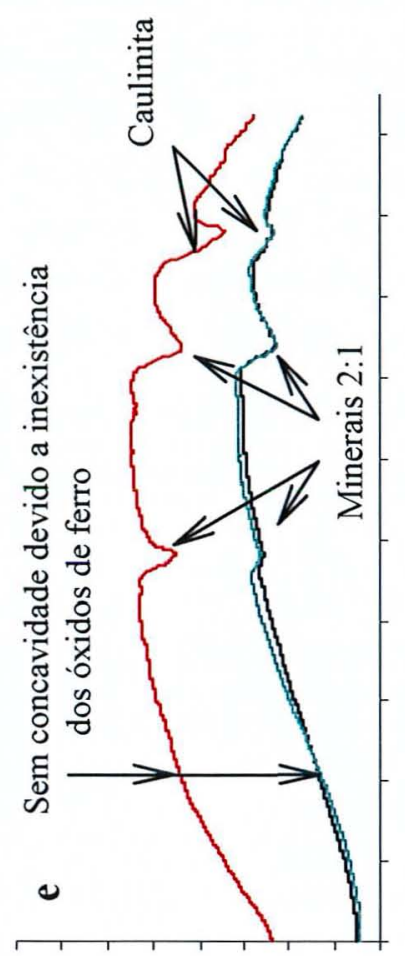

$\infty N 0$ n t m n

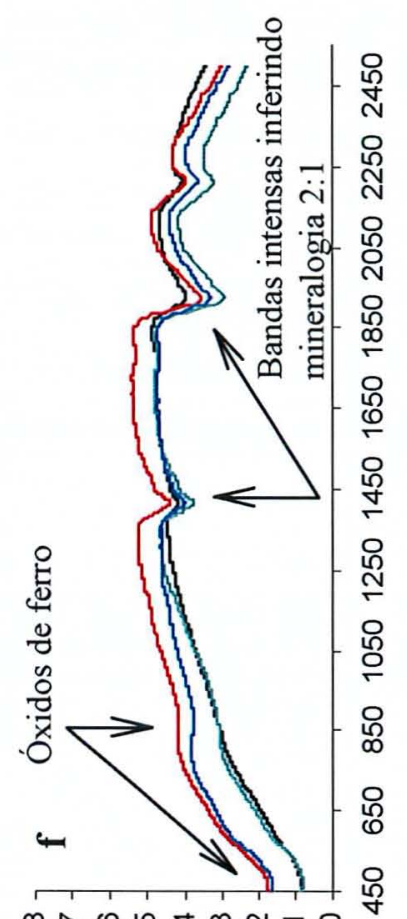

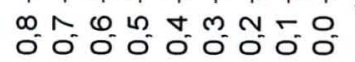

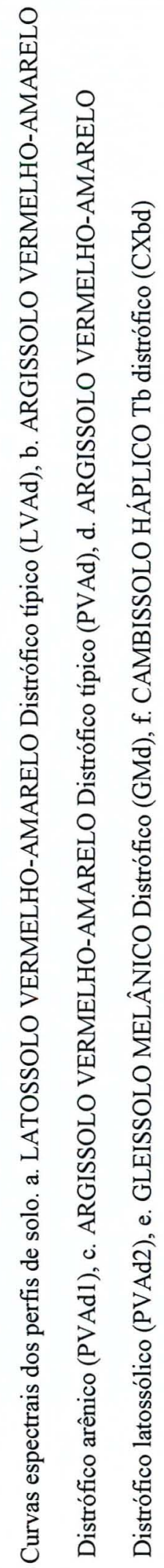

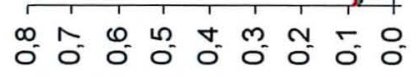

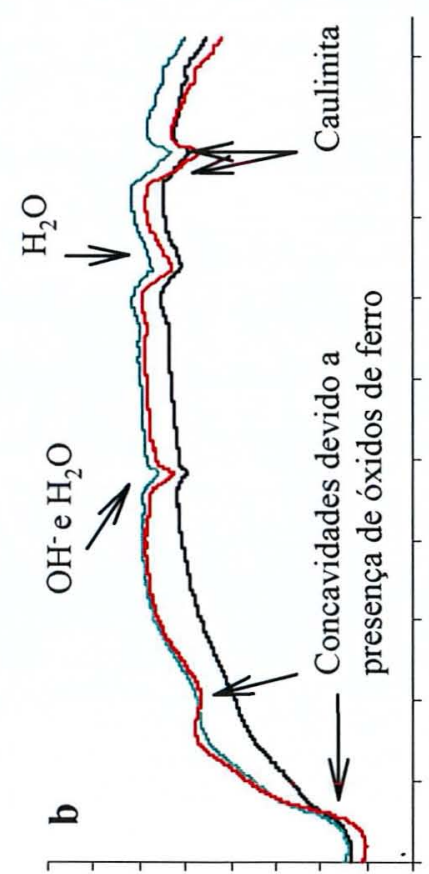

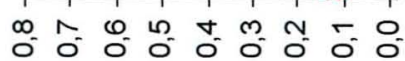

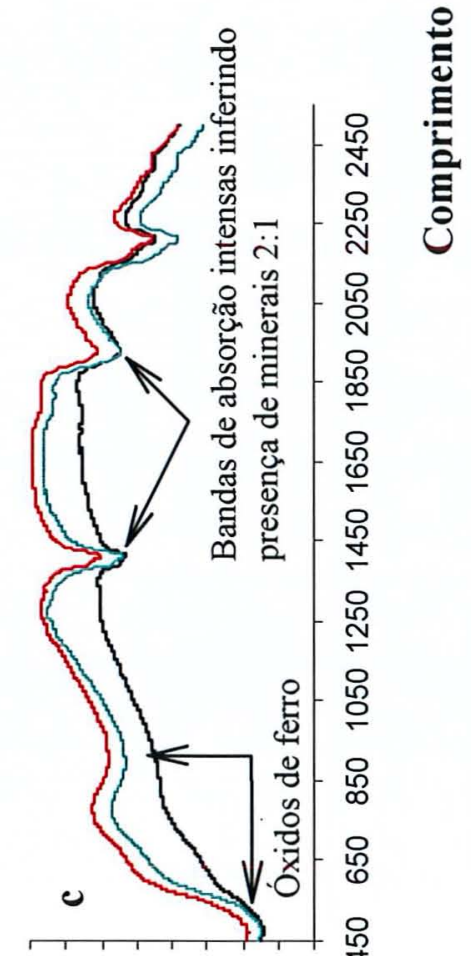

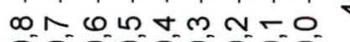




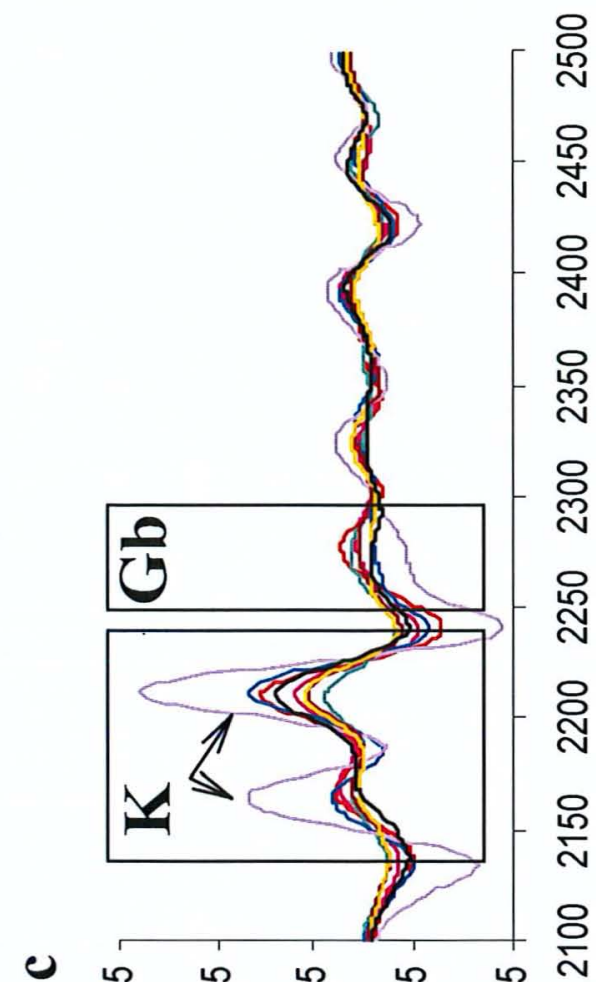

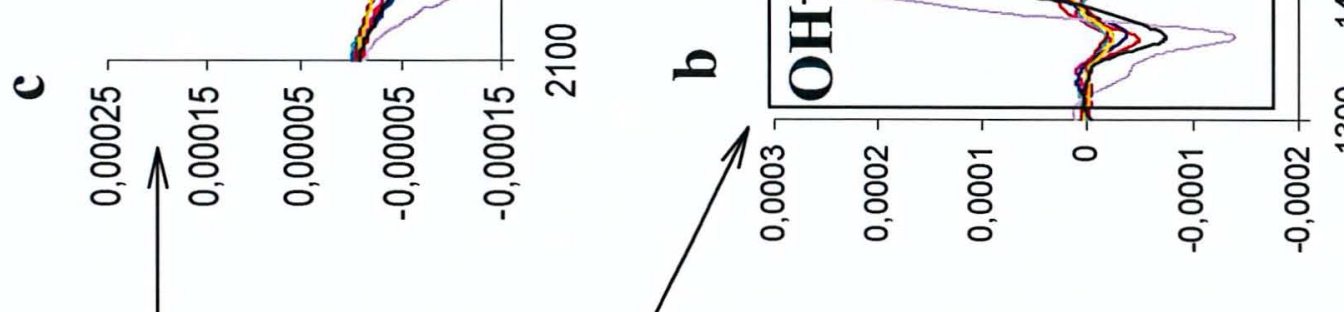
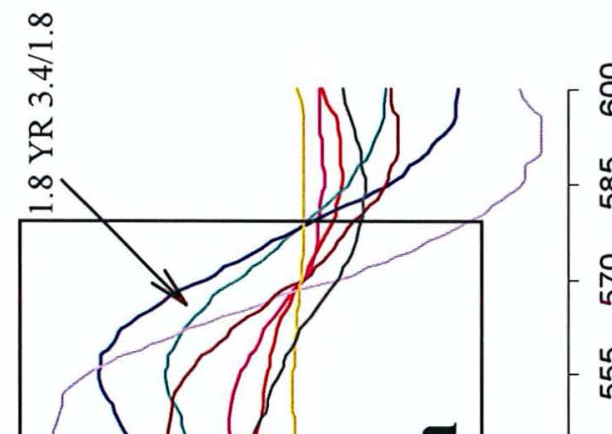

E

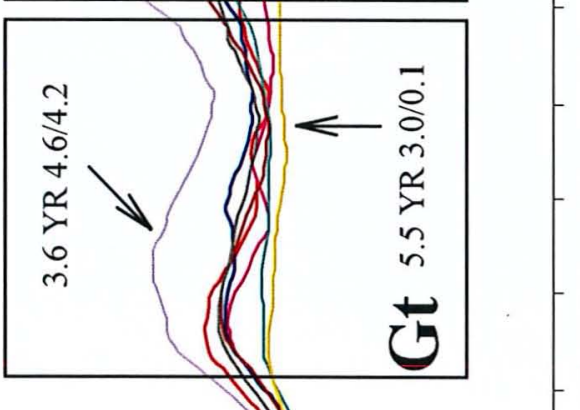

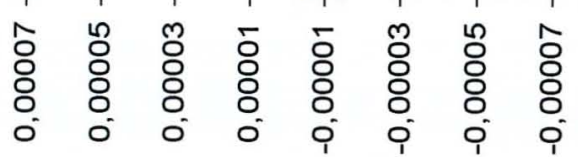

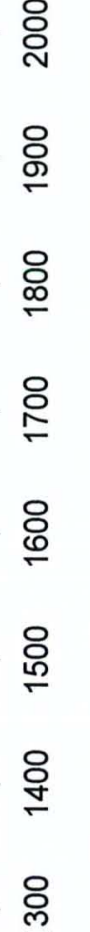




\section{DETERMINAÇÃO DE TEORES DE ATRIBUTOS DO SOLO POR MEIO DA ENERGIA ELETROMAGNÉTICA REFLETIDA}

\section{Resumo}

O objetivo do presente trabalho foi determinar o teor de atributos físicos, químicos e mineralógicos de 9 classes de solo a partir de sensor em laboratório. Para tal, montou-se um banco de dados com 3300 amostras de terra e suas respectivas análises e radiometria dos Estados de São Paulo e Paraná. Pela utilização dos dados espectrais foram obtidas equações de regressão múltipla para 20 atributos do solo. Os atributos físicos e mineralógicos apresentaram, em sua maior parte, coeficientes maiores que 0,70 , enquanto que para os atributos químicos este valor foi, de maneira geral, menor que 0,50 . Os atributos cujo modelo obteve $\mathrm{R}^{2}>0,50$ foram testados em amostras de terra que não participaram do geração do modelo. Os valores estimados através da equação foram então comparados com os valores determinados em laboratório. Areia, silte, argila, $\mathrm{Fe}_{2} \mathrm{O}_{3}, \mathrm{SiO}_{2}, \mathrm{TiO}_{2}, \mathrm{Al}_{2} \mathrm{O}_{3}, \mathrm{Ki}$ e $\mathrm{Kr}$ apresentaram resultados estatisticamente semelhantes entre os dados estimados e os determinados. Os resultados indicam que é possível determinar o teor desses atributos pela metodologia adotada.

\section{DETERMINATION OF SOIL ATTRIBUTES CONTENTS BY ELETROMAGNETIC REFLECTED ENERGY}

\section{Summary}


The objective of the present work was to determine soil physical, chemical and mineralogical attributes of 9 soil classes by laboratory sensor. For this, a databank was created with 3300 soil samples and their respective analysis and radiometric data in the states of São Paulo and Paraná. Using the spectral data multiple regression models were generated for 20 attributes. Most of mineralogical and physical attributes presented a coefficient higher than 0,70 , while the chemical attributes were, in a normal way, lower than 0,50 . The attributes with $\mathrm{R}^{2}>0,50$ were tested in samples that did not participate of models creation. The esteemed values obtained through the equation were compared with the determined values obtained by the laboratory. Sand, silt, clay, $\mathrm{Fe}_{2} \mathrm{O}_{3}, \mathrm{SiO}_{2}$, $\mathrm{TiO}_{2}, \mathrm{Al}_{2} \mathrm{O}_{3}, \mathrm{Ki}$ and $\mathrm{Kr}$ presented similar results among the esteemed sensor data and laboratory data. The results indicate that it is possible to determine the content of these attributes by the adopted methodology.

\subsection{Introdução}

O manejo adequado de um sistema agrícola está vinculado ao aumento de produtividade sem que haja danos ao meio ambiente e, para tanto, é necessário que seja realizado um planejamento agrícola da região. A base deste planejamento está no conhecimento da distribuição espacial das diversas classes de solos e, consequentemente de suas propriedades químicas, físicas e mineralógicas sendo, o resultado da análise de solo, a metodologia utilizada para se obter grande parte das informações necessárias a esta atividade.

A determinação dos atributos do solo realizada por análises químicas, físicas e mineralógicas em laboratório, são as mais confiáveis considerando os anos de pesquisa e testes realizados para se chegar em métodos padronizados (Fiorio, 2002). Entretanto, estes procedimentos muitas vezes são complexos, caros e demorados principalmente quando um grande número de análises são necessárias.

Desta forma, novas metodologias vêm sendo desenvolvidas como o intuito de auxiliar esta atividade, principalmente com a implantação da Agricultura de Precisão, na qual, o número de amostras é maior e a necessidade de informações em tempo real é 
indispensável (Thomasson et al., 2001). Neste aspecto, a utilização do espectro eletromagnético, na faixa do visível ao infra vermelho, vêm se mostrando eficaz pois permite analisar vários constituintes de um material ao mesmo tempo, em uma análise rápida, de baixo custo e com pouca ou nenhuma preparação das amostras (Stark et al., 1986; Chang et al., 2001).

O sistema NIRA (Near Infrared Analysis) foi inicialmente desenvolvido na década de 70 para determinar a umidade de grãos (Ben-Gera \& Norris, 1968) e atualmente é utilizado para vários fins, como determinar a qualidade de grãos, forragens, identificar e caracterizar produtos químicos e farmacêuticos (Chang et al., 2001).

A estimativa de atributos do solo a partir de sua resposta espectral na faixa do visível ao infra vermelho, têm sido realizada e bons resultados vêm sendo obtidos para conteúdo de matéria orgânica, argila e óxidos de ferro (Coleman et al., 1991); superfície específica e CTC (Ben-Dor \& Banin, 1995a); teor de cálcio, magnésio, fósforo e potássio (Janik et al., 1998); pH, relação Ca:Mg (Dunn et al., 2002); umidade do solo (Lobell \& Asner, 2002); $\mathrm{SiO}_{2}, \mathrm{TiO}_{2}$ e $\mathrm{Fe}_{2} \mathrm{O}_{3}, \mathrm{Al}_{2} \mathrm{O}_{3}$ (Fiorio, 2002).

Entretanto, alguns dos resultados obtidos envolvem um número limitado de amostras ou são provenientes de locais com tipos de solos similares. Sendo assim, para que a resposta espectral do solo como método analítico possa ser usada para fins comerciais, é necessário que vários tipos de solos em diferentes regiões sejam avaliados.

Neste sentido, este trabalho tem por objetivo estimar atributos físicos (teor de areia, silte e argila), químicos (matéria orgânica, soma de bases, CTC, V\%, m\%, pH em $\mathrm{CaCl}_{2}$, fósforo, potássio, cálcio e magnésio) e mineralógicos $\left(\mathrm{SiO}_{2}, \mathrm{TiO}_{2}, \mathrm{Fe}_{2} \mathrm{O}_{3}, \mathrm{Al}_{2} \mathrm{O}_{3}\right.$,

$\mathrm{MnO}_{2}$, Ki e $\mathrm{Kr}$ ) a partir da resposta espectral obtida por sensor em laboratório de amostras de solo coletadas de diferentes classes de solos nos Estados de São Paulo e Paraná. Sabendo-se da íntima relação entre os dados espectrais e as características do solo, espera-se que seus teores possam ser determinados.

\subsection{Material e Métodos}

\subsubsection{Caracterização dos solos e áreas de estudo}


A partir de informações adquiridas do Laboratório de Sensoriamento Remoto do Departamento de Solos e Nutrição de Plantas da ESALQ, USP, montou-se um banco de dados com os resultados de análises químicas, granulométricas e mineralógicas e dados de radiometria de 9 ordens de solos das seguintes áreas: Arapoti, no Estado do Paraná; Mogi Mirim, Mogi Guaçú, Piracicaba, Rafard, Barra Bonita e Lençóis Paulista no Estado de São Paulo (Tabela 1) abrangendo uma área aproximada de 100.750 ha. Foram avaliadas 3300 amostras de terra, das profundidades 0-20, 40-60 cm chamadas de camadas A e B, respectivamente. Os solos analisados foram descritos (Lemos \& Santos, 1996) e classificados (Embrapa,1999).

\subsubsection{Análises químicas e granulométricas}

As amostras de terra foram analisadas quimicamente para determinar: $\mathrm{pH}\left(\mathrm{CaCl}_{2}\right)$, teor de matéria orgânica, fósforo, potássio, magnésio, cálcio, alumínio e hidrogênio mais alumínio, segundo metodologia descrita em Raij et al. (1987). Os teores de areia, silte e argila foram determinados de acordo com Camargo et al. (1986) e a sílica, alumínio, manganês, titânio e ferro foram determinados pelo ataque sulfúrico (Camargo et al., 1986).

\subsubsection{Obtenção dos dados radiométricos}

O método de obtenção dos dados radiométricos que compõem o banco de dados é a seguir descrito. As amostras de terra encaminhadas para laboratório foram secas em estufa por $24 \mathrm{~h}$ à $45^{\circ} \mathrm{C}$, moídas e peneiradas (malha de $2 \mathrm{~mm}$ ). A reflectância foi obtida utilizando-se o espectrorradiômetro Infra Red Intelligent Spectroradiometer (IRIS), com resolução de $2 \mathrm{~nm}$ entre 400 e $1100 \mathrm{~nm}$ e $4 \mathrm{~nm}$ entre 1100 e $2500 \mathrm{~nm}$ e utilizou-se uma placa de referência com 100 \% de reflectância como padrão.

As amostras foram acondicionadas em placas de petri com $9 \mathrm{~cm}$ de diâmetro e $1,5 \mathrm{~cm}$ de altura, localizada à $61 \mathrm{~cm}$ da fonte de iluminação (lâmpada halógena de 650 W com refletor parabólico e feixe não colimado) e à $27 \mathrm{~cm}$ do sensor. A lâmpada foi 
colocada à um ângulo de $15^{\circ}$ ao nadir. A energia elétrica foi estabilizada por uma fonte de potência para evitar distúrbios de intensidade na iluminação.

Os dados foram posteriormente calibrados e filtrados por software específico denominado Conviris (Steffen, 1997), eliminando o excesso de ruídos para facilitar a interpretação dos resultados. A relação entre a energia refletida pelo alvo e a energia refletida pela placa de referência gerou o fator de reflectância bidirecional (Nicodemus et al.,1977).

\subsubsection{Análise estatística}

A análise estatística foi realizada entre os dados de reflectância obtidos em laboratório com os atributos (teor de areia, silte e argila), químicos (matéria orgânica, soma de bases, $\mathrm{CTC}, \mathrm{V} \%, \mathrm{~m} \%, \mathrm{pH}$ em $\mathrm{CaCl}_{2}$, fósforo, potássio, cálcio e magnésio) e mineralógicos $\left(\mathrm{SiO}_{2}, \mathrm{TiO}_{2}, \mathrm{Fe}_{2} \mathrm{O}_{3}, \mathrm{Al}_{2} \mathrm{O}_{3}, \mathrm{MnO}_{2}, \mathrm{Ki}\right.$ e $\left.\mathrm{Kr}\right)$ dos solos. Foram selecionadas para os dados espectrais 22 bandas $(B)$ e 13 alturas $(H)$ (em nm) (Figura 1): B1: 420-48, B2: 481, B3: 481-596, B4: 596-710, B5: 710-814, B6: 814-975, B7: 975-1350, B8: 1350-1417, B9: 1417, B10: 1417-1449, B11: 1449-1793, B12: 1793-1831, B13: 18651927, B14: 1927, B15: 1927-2102, B16: 2101-2139, B17: 2139-2206, B18: 2206, B19: 2206-2258, B20: 2258, B21: 2258-2389, B22: 2389-2498; H1: 469-532, H2: 532-768, H3: 768-876, H4: 876-1353, H5: 1353-1411, H6: 1411-1439, H7: 1439-1783, H8: 1860 1923, H9: 1923-2120, H10: 2120-2206, H11: 2206-2258, H12: 2258-2389, H13: 23892498, sugeridas por Nanni \& Demattê (2001).

Inicialmente, foi realizada a seleção de variáveis (bandas e alturas) para cada atributo do solo através da análise stepwise. Em seguida, realizou-se o teste de multicolinearidade para eliminação de uma ou mais variáveis que atuavam concomitantemente na estimativa de um mesmo atributo, o que causava uma super estimativa deste atributo. Logo após, gerou-se o modelo estatístico, utilizando-se 2500 amostras de terra das duas camadas, através de regressão linear múltipla. Estas análises foram realizadas pelo Sistema de Análise Estatística SAS (SAS, 1999). 
Posteriormente, valores estimados foram gerados com 790 amostras destinadas para teste. Estes valores foram obtidos apenas para os atributos cujo $\mathrm{R}^{2}$ da equação de regressão múltipla apresentou valores maiores que 0,50 . Em seguida realizou-se teste $t$ para verificar a igualdade entre as médias dos valores determinados em análise de laboratório e os estimados por radiometria.

\subsection{Resultados e Discussão}

Equações de regressão múltipla foram geradas para a estimativa de 20 atributos de solos sendo três atributos relativos a constituição granulométrica (areia, silte e argila), sete a composição mineralógica $\left(\mathrm{SiO}_{2}, \mathrm{TiO}_{2}, \mathrm{Fe}_{2} \mathrm{O}_{3}, \mathrm{Al}_{2} \mathrm{O}_{3}, \mathrm{MnO}_{2}, \mathrm{Ki}\right.$ e $\left.\mathrm{Kr}\right)$ e dez relacionados a parte química (matéria orgânica, soma de bases, $\mathrm{CTC}, \mathrm{V} \%, \mathrm{~m} \%, \mathrm{pH}$ em $\mathrm{CaCl}_{2}$, fósforo, potássio, cálcio e magnésio). Tais modelos foram gerados através da resposta espectral das amostras de solo obtida em laboratório independente da profundidade, diferindo da metodologia de Nanni (2000) que gerou equações de regressão múltipla para as camadas superficial e subsuperficial separadamente.

\subsubsection{Equações de regressão múltipla para estimativa de atributos físicos e mineralógicos}

As equações geradas para os atributos físicos e mineralógicos (Tabela 2), apresentaram valor de $\mathrm{R}^{2}$ maior que 0,50 sendo que $\mathrm{o} \mathrm{MnO}_{2}$ e a fração silte foram os que apresentaram os menores valores com 0,51 e 0,57 respectivamente. Demattê (1999) obteve coeficiente mais elevados para os mesmos atributos com 0,86 para $\mathrm{MnO}_{2}$ e 0,63 para silte e Janik et al. (1998) com 0,84 para silte. Entretanto, outros autores obtiveram valores mais baixos para silte como Coleman et al. (1991) com $\mathrm{R}^{2}$ de 0,49 , Demattê \& Garcia (1999b) com 0,33, Nanni (2000) com 0,26 e 0,44 para camada superficial e subsuperficial respectivamente e Fiorio (2002) com $\mathrm{R}^{2}$ de 0,56 .

A granulometria é uma das principais características que influenciam na resposta espectral dos solos. Solos mais arenosos apresentam alta reflectância, enquanto solos 
argilosos baixa (Formaggio et al., 1996). Por outro lado, os componentes de cada fração (óxidos, quartzo, magnetita, ilmenita, enter outros) têm influência importante. Devido a esta característica (ou seja, aos inúmeros componentes de cada fração), as frações areia e argila foram os atributos que apresentaram o maior número de variáveis dependentes no modelo, 26 e 27 , entre bandas e alturas, respectivamente para areia e argila.

De forma geral, estes dois atributos físicos são os que geram valores de $\mathrm{R}^{2}$ mais expressivos sendo, normalmente, mais elevados que 0,70 , como os obtidos neste trabalho $(0,74$, para areia e argila) (Tabela 2) concordando com Nanni (2000) que obteve o mesmo valor $(0,74)$ para areia em superfície. Por outro lado, o mesmo autor verificou um coeficiente mais elevado $(0,82)$ em subsuperfície para o mesmo atributo.

Coeficientes de determinação mais significativo que os obtidos no presente trabalho foram observados por Janik et al. (1998) com 0,94 para areia e 0,79 para argila, assim como por Demattê \& Garcia (1999a), trabalhando com solos derivados de basalto no Estado do Paraná, com 0,90 para argila e Fiorio (2002), com solos da região de Barra Bonita, com 0,85 para argila e 0,81 para areia. Portanto, os resultados do presente trabalho ratificam vários em literatura, sobre a correlação entre teor de areia e argila com as respostas espectrais, levando a ter segurança na quantificação.

Dentre os atributos mineralógicos (Tabela 2), verifica-se que $\mathrm{SiO}_{2}, \mathrm{TiO}_{2}, \mathrm{Fe}_{2} \mathrm{O}_{3}$, $\mathrm{Al}_{2} \mathrm{O}_{3}$ obtiveram bons coeficientes variando de $0,71\left(\mathrm{Fe}_{2} \mathrm{O}_{3}\right)$ a $0,90\left(\mathrm{SiO}_{2}\right)$. Tais valores são menores do que aqueles determinados por Nanni \& Demattê (2001) com $\mathrm{R}^{2}$ maiores que 0,9 para $\mathrm{Fe}_{2} \mathrm{O}_{3}, \mathrm{SiO}_{2}$ e $\mathrm{TiO}_{2}$ para solos da região de Piracicaba. Sendo que valores mais baixos que os aqui obtidos foram verificados por Fiorio (2002) com 0,72 para $\mathrm{SiO}_{2}$ e 0,64 para $\mathrm{Fe}_{2} \mathrm{O}_{3}$ por Demattê \& Garcia (1999a).

Os indices de intemperismo, $\mathrm{Ki}$ e $\mathrm{Kr}$, foram os que apresentaram os melhores resultados com $R^{2}$ de 0,90 e 0,97 , respectivamente. Valores mais baixos foram observados por Demattê \& Garcia (1999b) para Ki com $\mathrm{R}^{2}$ de 0,39 e Fiorio (2002) com $\mathrm{Kr}$ de 0,67 e $\mathrm{Ki}$ de 0,42 .

Os valores de $\mathrm{R}^{2}$ obtidos para os atributos físicos e mineralógicos foram considerados satisfatórios tornando as equações confiáveis para serem usadas na estimativa destes elementos. Altas correlações desses atributos com características 
espectrais dos solos também foram obtidas por Galvão et al. (1997) e Ben-Dor et al. (1999). Para o caso dos atributos mineralógicos, a sua quantificação é de grande importância principalmente para classificação de solos, visto que a análise mineralógica tradicional é o ataque sulfúrico. Esta análise é de alto custo, demorada e cujos resultados são constantemente colocados em discussão, haja visto as intensas alterações químicas provocadas pelos produtos utilizados. A análise radiométrica é não destrutiva e de rápida obtenção, e os resultados de anos de pesquisa ratificam o aqui observado sobre a alta correlação entre estes atributos e a reflectância, podendo portanto ser quantificados.

\subsubsection{Equações de regressão múltipla para estimativa de atributos químicos}

A Tabela 3 apresenta os modelos desenvolvidos para estimar os atributos químicos do solo sendo eles, matéria orgânica, soma de bases, CTC, V\%, m\%, pH em $\mathrm{CaCl}_{2}$, fósforo, potássio, cálcio e magnésio.

Quimicamente, as equações apresentaram coeficientes de determinação baixos sendo que apenas matéria orgânica (MO) e saturação por alumínio (m\%) apresentaram valores maiores que 0,50 (Tabela 3 ). O resultado verificado para $M O$ com $R^{2}$ de 0,53 é melhor do que os observados por Demattê \& Garcia (1999a), Fiorio (2002) e Ben-Dor \& Banin (1995b). Fica claro que os coeficientes relativos à matéria orgânica são muito variáveis. Portanto, há a necessidade de maiores estudos sobre a matéria orgânica devido as suas fases de decomposição, que apresentam respostas espectrais distintas em todo o espectro eletromagnético (Henderson et al., 1992). Para o m\%, cujo coeficiente foi de 0,51 , Nanni (2000) obteve 0,32 enquanto Fiorio (2002) observou um coeficiente considerado satisfatório de 0,68 .

Para CTC, soma de bases, V e pH verificou-se valores em torno de 0,40 (Tabela 3), próximo dos obtidos por Fiorio (2002) e Demattê \& Garcia (1999b) e diferente daqueles obtidos por Nanni \& Demattê (2001) onde o $\mathrm{R}^{2}$ para CTC foi de 0,90 e Janik et al. (1998) que apresentou para $\mathrm{pH} \mathrm{R}^{2}$ de 0,64 e 0,84 para SB. 
Dentre os atributos químicos, as bases foram os elementos que obtiveram os menores coeficientes de determinação, ficando em torno de 0,1 (Tabela 3) tornando tais modelos pouco confiáveis. Resultados similares foram obtidos por Demattê (1999) e Demattê \& Garcia (1999b) com coeficientes em torno de 0,3 para K, Ca, P e Mg. Dunn et al. (2002), no entanto, obteve coeficientes acima de 0,80 para $\mathrm{Ca}$ e $\mathrm{Mg}$ assim como Janik et al. (1998) e Malley et al. (1999) para os mesmos elementos.

A base dos artigos em literatura para o assunto é igual, ou seja, utilizam o NIRA (Ben-Gera \& Norris, 1968). A forma de determinação dos modelos é variável, bem como o tamanho das áreas, número de amostras e profundidade de amostragem. De forma geral, os coeficientes de determinação para os elementos químicos foram mais baixos que os citados na literatura. Tal fato pode ser explicado pelo número de amostras aqui utilizado (2500) que foi maior do que os empregados nestes trabalhos o que causa grande diversidade de solos e consequentemente de seus atributos químicos, proporcionando uma grande dispersão de pontos em torno da média, reduzindo o $\mathrm{R}^{2}$. Além disso, a área de abrangência é grande, com aproximadamente 100.000 ha, contra 250 e 500 ha observados por Nanni (2000) e Fiorio (2002) respectivamente.

Considere-se ainda que os elementos químicos como por exemplo as bases trocáveis, não são considerados atributos com grande interferência na reflectância. $\mathrm{Ou}$ seja, para a sua detecção são necessários delineamentos e avaliações mais detalhadas, conforme realizado por Dunn et al. (2002).

\subsubsection{Avaliação dos valores determinados em laboratório com os estimados através das equações de regressão}

Com a finalidade de verificar a possibilidade de utilização das equações de regressão, na predição dos atributos aqui estudados, amostras de terra não utilizadas para gerar o modelo foram testadas, obtendo-se desta forma os valores estimados (VE) que foram comparados aos valores determinados pela análise de laboratório (VD). Foram testados os modelos de areia, silte, argila, $\mathrm{MO}, \mathrm{m} \%, \mathrm{SiO}_{2}, \mathrm{TiO}_{2}, \mathrm{Fe}_{2} \mathrm{O}_{3}, \mathrm{Al}_{2} \mathrm{O}_{3}, \mathrm{MnO}_{2}$, $\mathrm{Ki}$ e $\mathrm{Kr}$ por apresentarem $\mathrm{R}^{2}$ maior que 0,50 . 
A Tabela 4 apresenta os dados comparativos das médias, entre os valores estimados e os valores determinados, pelo teste $t$. Verifica-se que, a utilização dos modelos para predição dos atributos do solo possibilitou a estimativa de valores estatisticamente semelhantes aos determinados em laboratório para praticamente todos os atributos testados só diferindo a $\mathrm{MO}$ e o $\mathrm{m} \%$. Tal resposta está relacionada ao fato destes dois atributos ( $\mathrm{MO}$ e $\mathrm{m} \%$ ) terem o menor valor de $\mathrm{R}^{2}$ dentre todos os atributos testados.

Resultado semelhante foi obtido por Nanni (2000) no qual as médias entre VE e VD para MO e m\% também diferiram estatisticamente enquanto, para argila e silte não houve diferença. Por outro lado, os resultados de Fiorio (2002) diferem parcialmente visto que $\mathrm{MO}$ e $\mathrm{m} \%$ não apresentaram diferenças estatísticas. Desta forma, o que se observa é que é possível estabelecer modelos que auxiliem na estimativa de atributos dos solos, porém, para o caso da $\mathrm{MO}$ e $\mathrm{m} \%$ os resultados não são conclusivos devido às variações observadas.

\subsection{Conclusões}

1- As equações de regressão múltipla apresentaram coeficientes de determinação elevados para atributos físicos e mineralógicos de solos, a partir de um grande número de amostras, independente da camada de terra amostrada.

2- A determinação dos atributos químicos do solo como cálcio, magnésio, fósforo e potássio não é possível a partir da energia eletromagnética refletida conforme demostrado pelas equações com baixas correlações. São necessários novos estudos para estas variáveis, tendo-se como sugestão a avaliação de áreas com menor extensão.

3- A determinação de teores de atributos do solo como areia, silte, argila, $\mathrm{SiO}_{2}, \mathrm{Al}_{2} \mathrm{O}_{3}$, $\mathrm{TiO}_{2}$ e $\mathrm{Fe}_{2} \mathrm{O}_{3}$ pode ser realizada pela energia eletromagnética refletida utilizando-se a metodologia proposta neste trabalho. 
Tabela 1. Locais de amostragem, classes de solos, número de amostras e área aproximada das áreas utilizadas para a montagem do banco de dados.

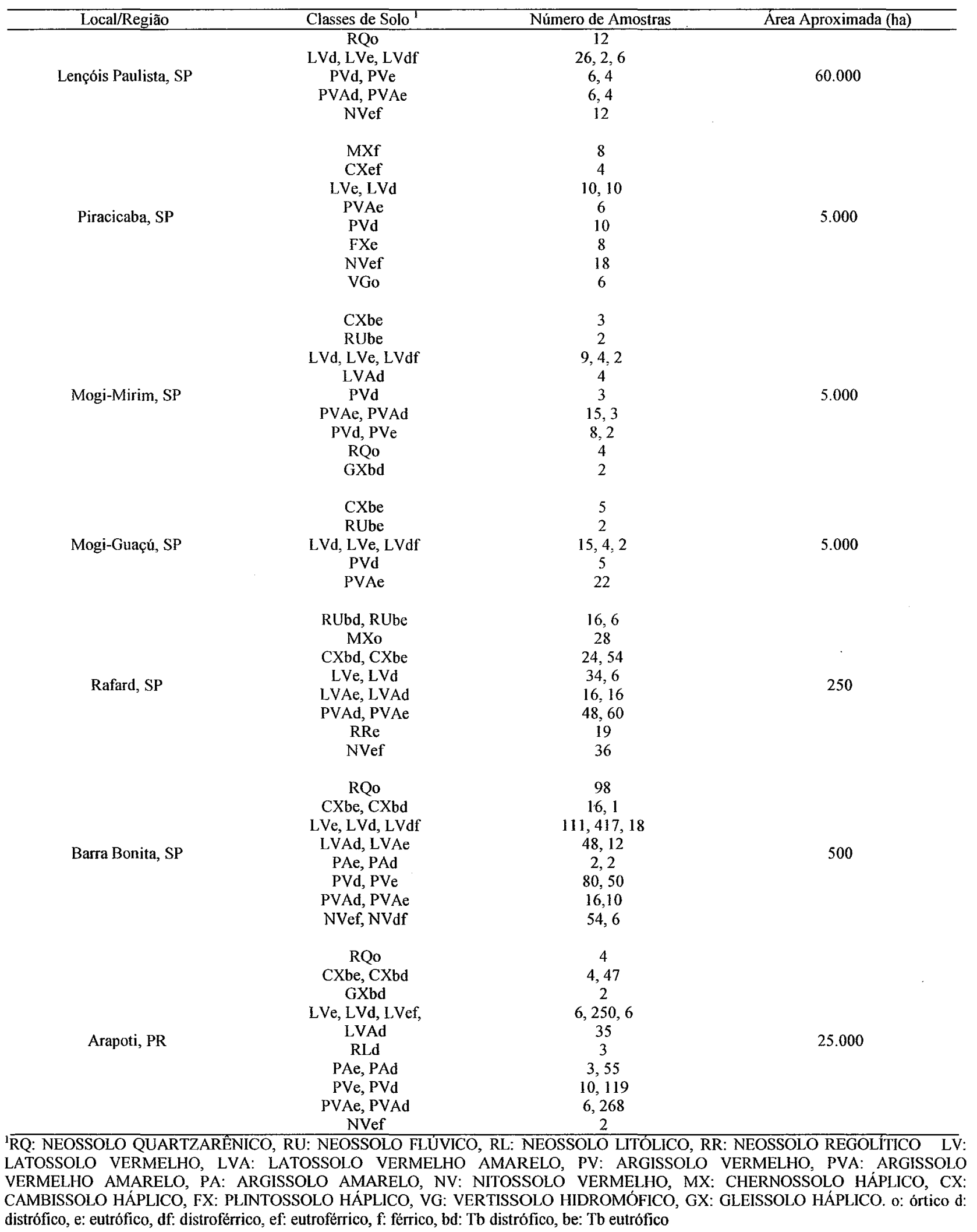




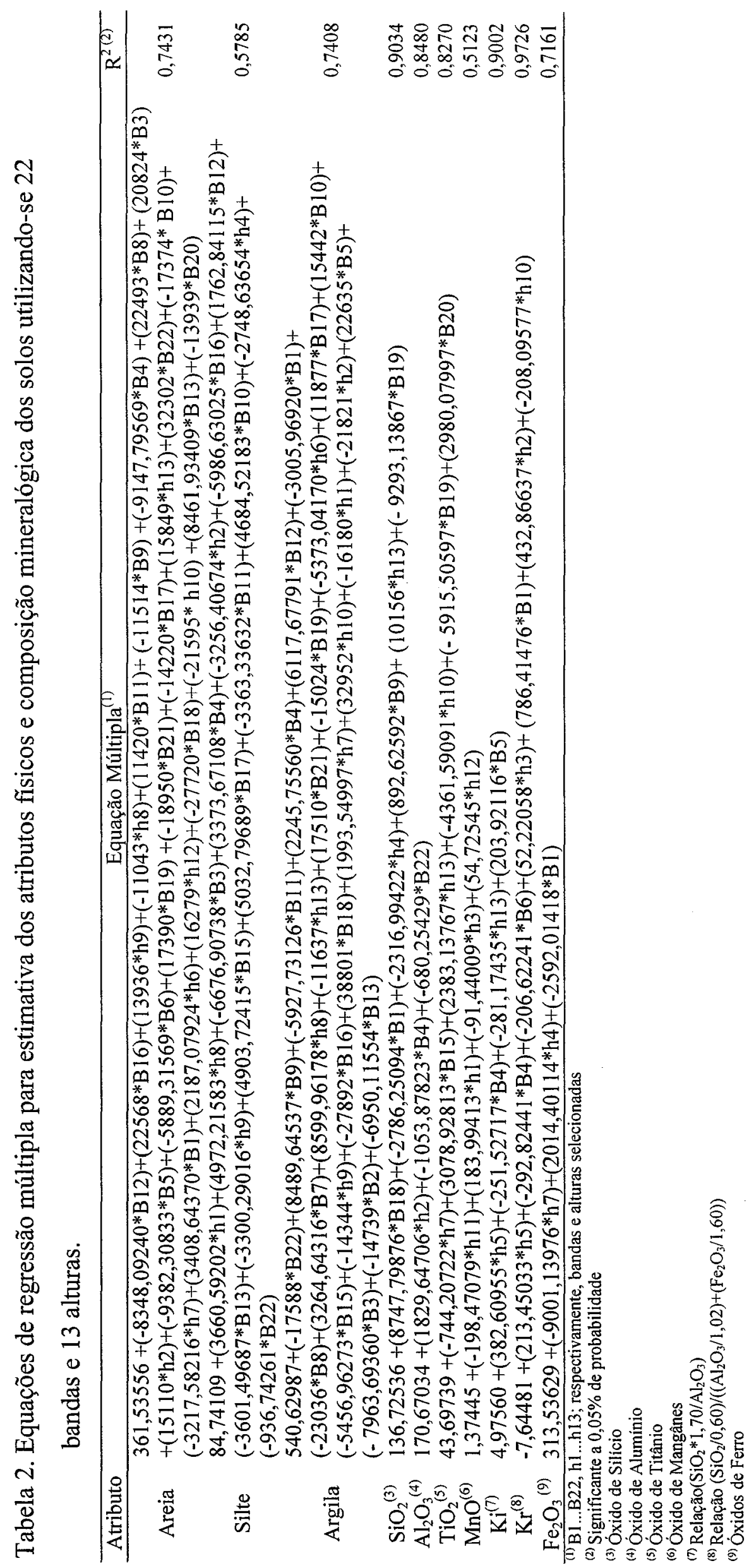




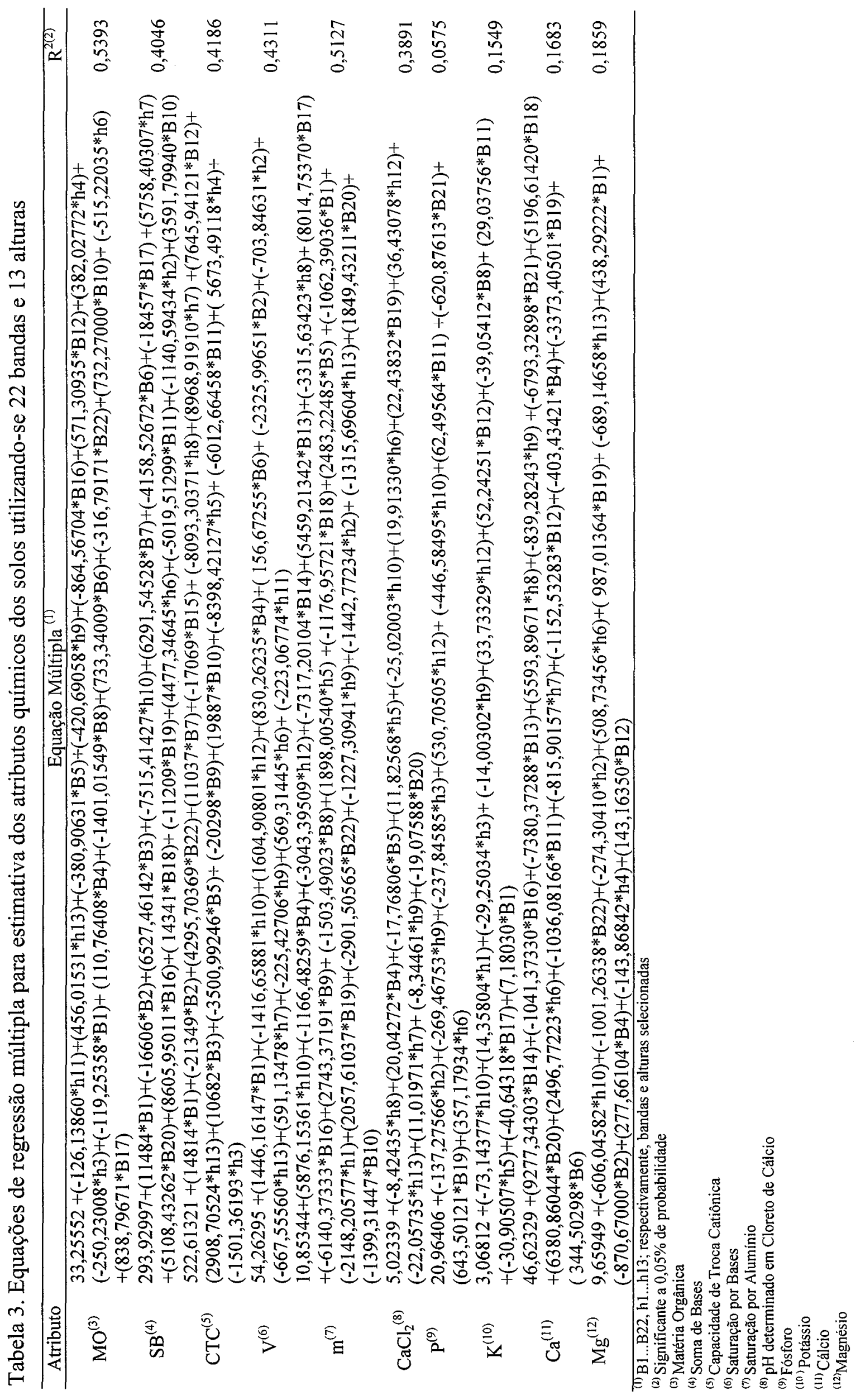




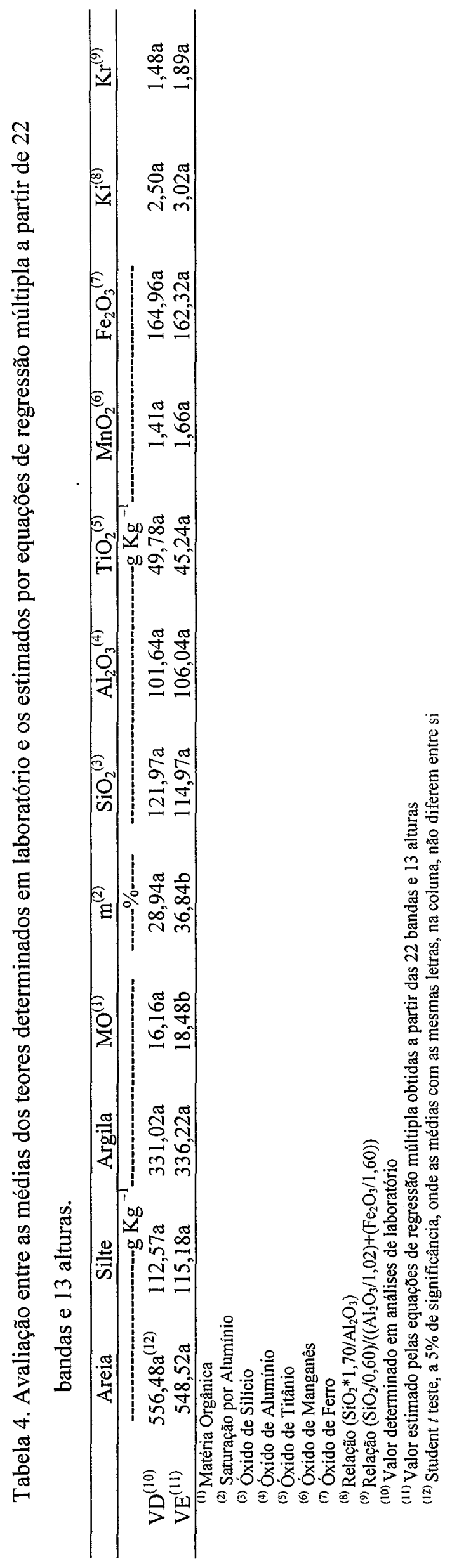


a.

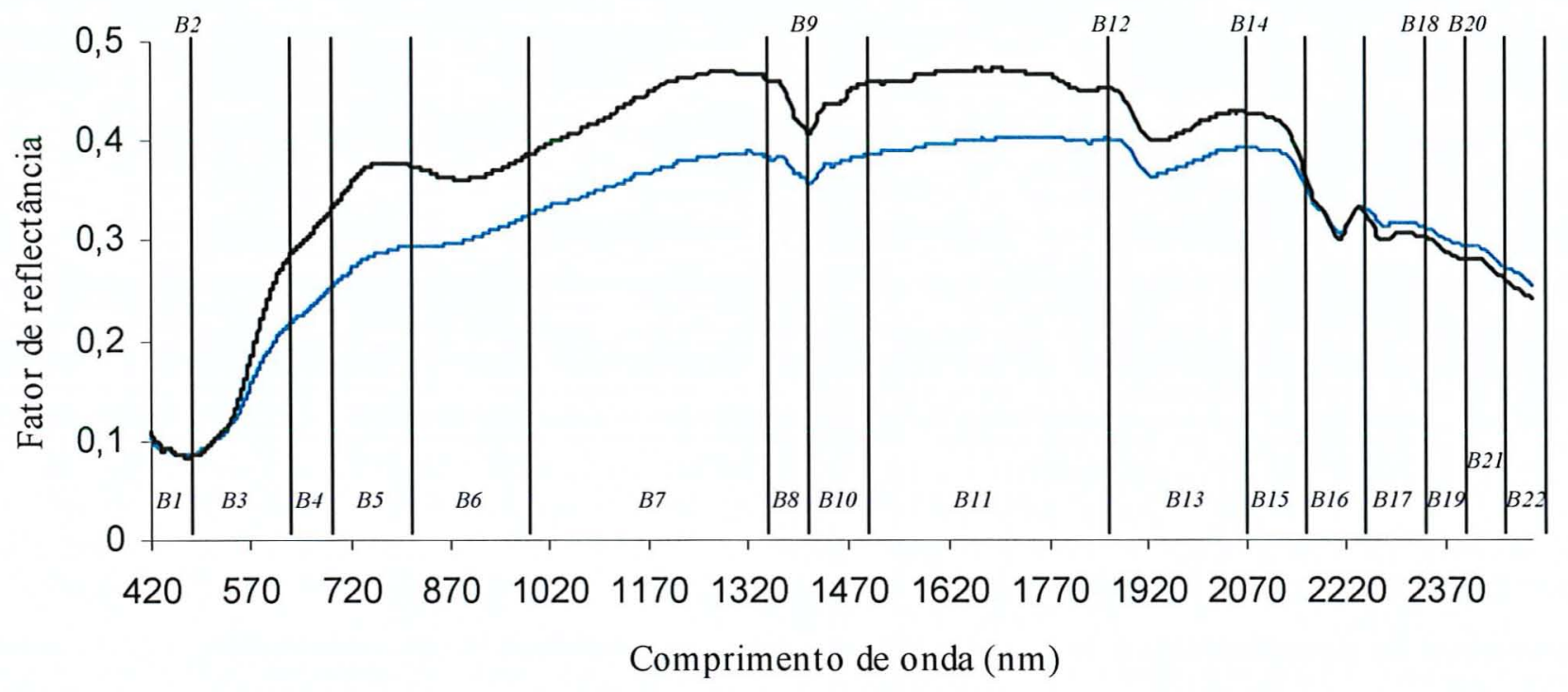

b.

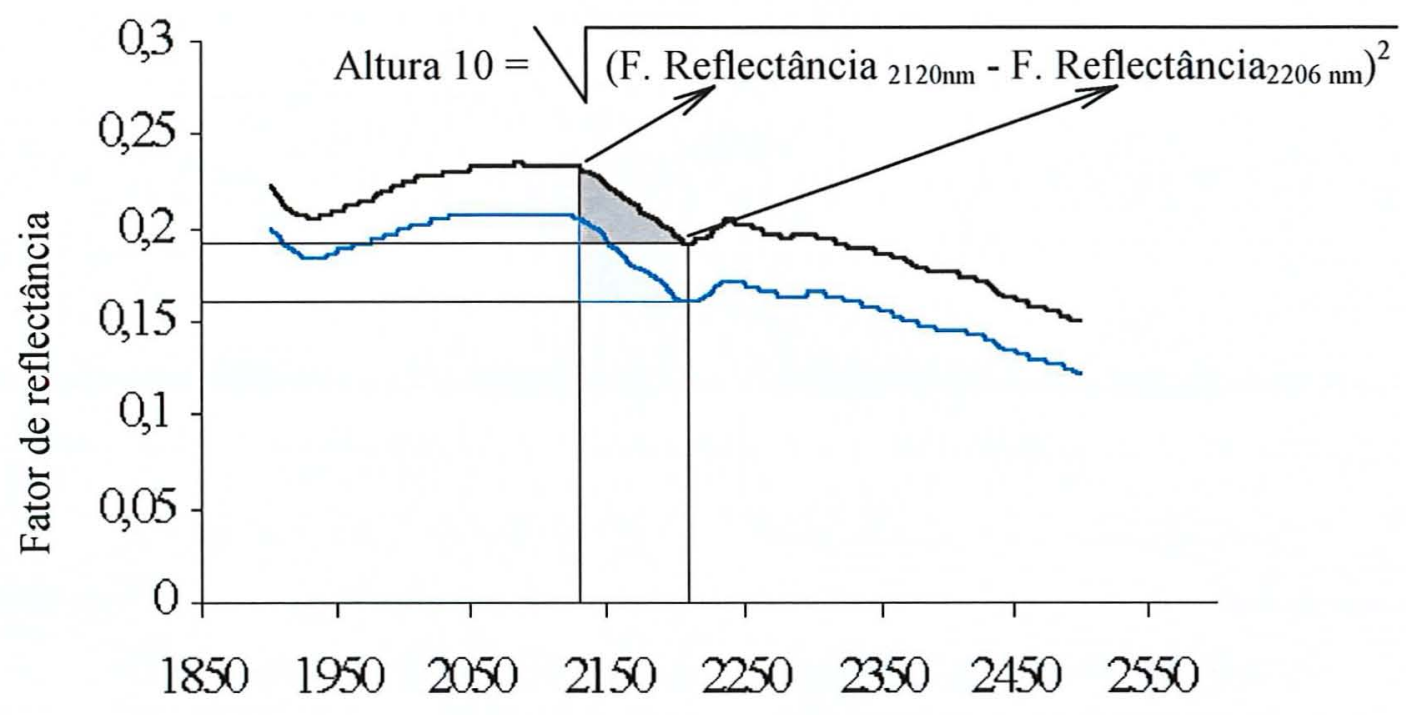

Comprimento de onda $(\mathrm{nm})$

Figura 1 - a. Representação das 22 bandas escolhidas nas curvas espectrais obtidas em laboratório e b. Representação da obtenção da altura 10 (H10) entre a crista e o vale da inflexão observada no intervalo entre $2120 \mathrm{~nm}$ e $2206 \mathrm{~nm}$. 


\section{QUANTIFICAÇÃO DE ATRIBUTOS QUÍMICOS DE SOLOS ATRAVÉS DE DADOS RADIOMÉTRICOS COM VISTAS À AGRICULTURA DE PRECISÃO}

\section{Resumo}

Uma das primeiras e mais importantes áreas na qual a Agricultura de Precisão tem sido aplicada comercialmente é no manejo da fertilidade do solo. Com isso, o objetivo deste trabalho foi predizer o teor de atributos químicos do solo a partir de sua resposta espectral obtida em laboratório. A área de estudo localiza-se no município de Uberlândia, MG, com 1000 ha. Foram estabelecidos 30 pontos de tradagens dos quais amostras de terra foram coletadas em três profundidades $(0-20,40-60$ e 80-100 cm). As amostras foram analisadas química e fisicamente e, a radiometria foi obtida por sensor em laboratório na faixa de $400-2500 \mathrm{~nm}$. Foram geradas equações de regressão múltipla para matéria orgânica, soma de bases, CTC, saturação por bases (V), saturação por alumínio (m), $\mathrm{pH}$ em $\mathrm{CaCl}_{2}, \mathrm{P}, \mathrm{K}, \mathrm{Ca}, \mathrm{Mg}, \mathrm{Al}$ e $\mathrm{H}$ utilizando-se 60 amostras de solo. $\mathrm{H}, \mathrm{Al}, \mathrm{m}$ e $\mathrm{pH}$ obtiveram $\mathrm{R}^{2}<0,50$. As equações com $\mathrm{R}^{2}>0,50$ para os outros atributos foram testadas em 41 amostras de terra desconhecidas, gerando os valores estimados. Posteriormente, estes valores foram comparados aos valores determinados por análise convencional. Não houve diferença significativa entre as médias dos valores estimados e determinados para $\mathrm{MO}, \mathrm{SB}, \mathrm{CTC}, \mathrm{V} \%, \mathrm{P}, \mathrm{K}, \mathrm{Ca}$ e $\mathrm{Mg}$. Os resultados indicam ser possível determinar estes elementos com modelos específicos para esta região. A utilização de resultados de V\% e CTC determinados por dados espectrais, auxilia na recomendação de calagem, podendo ser aplicada em agricultura de precisão. 


\section{QUANTIFICATION OF CHEMICAL SOIL ATRIBUTTES THROUGH RADIOMETRIC DATA FOR USE IN PRECISION AGRICULTURE}

\section{Summary}

One of the first and most important areas in which Precision Agriculture is being commercially applied is in managing the variability of soil fertility. Herewith, the objective of the present work was to predict the content of chemical soil attributes by their spectral response obtained in laboratory. The study area is a 1000 ha field located in Uberlândia, MG. It was established 30 sampling points where soil was collected in 3 depths $(0-20,40-60$ and $80-100 \mathrm{~cm})$. The samples were analised chemically and physically and, the radiometric data was obtained by laboratory sensor in a $400-2500$ $\mathrm{nm}$ range. Multiple regression equation was generated for organic matter (OM), sum of bases (SB), CEC, saturation by bases (V\%), saturation by aluminium (m\%), $\mathrm{pH}\left(\mathrm{CaCl}_{2}\right)$, $\mathrm{P}, \mathrm{K}, \mathrm{Ca}, \mathrm{Mg}, \mathrm{Al}$ and $\mathrm{H}$ using 60 soil samples. $\mathrm{H}, \mathrm{Al}, \mathrm{m}$ and $\mathrm{pH}$ obtained $\mathrm{R}^{2}<0,50$. The equation with $\mathrm{R}^{2}>0,50$ for the others attributes were tested with 41 unknown soil samples and obtained the esteemed values. After that, these values were compared with those determinated by conventional analysis. No significative differences between esteemed and the determinated values was obtained for OM, SB, CEC, V\%, P, K, Ca e $\mathrm{Mg}$. The results indicated that it is possible to determine these elements with specific models for this region. The utilization of $\mathrm{V} \%$ and $\mathrm{CEC}$ results obtained by the spectral data is an auxiliary tool in lime recommendations and can be applied in Precision Agriculture.

\subsection{Introdução}

Os produtores agrícolas consideram que a área de produção é homogênea de tal forma que a quantidade de insumos requerida para a produção é aplicada em taxas constantes em toda a área (Borgelt et al., 1994). Entretanto, normalmente a área apresenta consideráveis diferenças nas suas características, principalmente quanto ao 
tipo de solo proporcionando níveis de produtividade variáveis. Por isso, a identificação de zonas de manejo, que leva em conta a distribuição de atributos do solo é importante na redefinição das práticas de manejo visando minimizar custos e maximizar a produção (Mapa \& Kumaragamage, 1996).

A aplicação de fertilizantes é, sem dúvida, um dos maiores custos na produção agrícola por isso, a determinação da melhor relação custo-benefício na utilização deste insumo é de grande importância (Bullock et al., 2000). Neste sentido, o sensoriamento remoto vem se mostrando uma fonte de informação valiosa no manejo da variabilidade da fertilidade do solo, principalmente depois da implantação da agricultura de precisão.

O método tradicional de se verificar a fertilidade do solo e conseqüentemente de se recomendar a aplicação de adubos vem do resultado das análises químicas de solos. $\mathrm{O}$ princípio básico deste método é amostrar a área de uma tal maneira que a análise destas amostras irão refletir fertilidade do solo da área (Borgelt et al., 1994; Thomasson et al., 2001).

A coleta de amostras para fins de fertilidade é, regra geral, de 1 amostra composta de 20 subamostras para uma área não maior do que 20 ha (Raij et al., 1996), gerando uma considerável oportunidade de erro. No caso da agricultura de precisão, é de 1 a 2,5 pontos/ha o que proporciona um alto custo (Fraisse, 1998). Aliás, Demattê et al. (2001a) demostraram que em Latossolos do Estado de São Paulo o recomendável é de 1 a 2 amostras/ha, sendo as amostras de terra o que mais onerou o custo de produção.

Desta forma, novos métodos de análise de solo que sejam menos onerosos e mais rápidos vêm sendo investigados. A aplicação da espectroscopia como método para análise de solos teve início após Bowers \& Hanks (1965) mostrarem que é possível quantificar atributos do solo, como umidade e matéria orgânica através da energia refletida.

Portanto, este trabalho objetiva quantificar atributos químicos do solo através de dados espectrais obtidos em laboratório e relacioná-los com o manejo químico. Com isso espera-se contribuir para o desenvolvimento de uma metodologia que venha automatizar a quantificação de atributos químicos dos solos como apoio a Agricultura de Precisão. 
Espera-se que a avaliação dos dados espectrais tenham relação com os atributos químicos do solo, sendo possível sua quantificação.

\subsection{Material e Métodos}

\subsubsection{Caracterização dos solos e área de estudo}

A área de estudo possui 1000 ha e localiza-se no município de Uberlândia, Minas Gerais nas coordenadas geográficas $19^{\circ} 27^{\prime}-1^{\circ} 23^{\prime} \mathrm{S}$ e $47^{\circ} 57^{\prime}-47^{\circ} 51^{\prime}$ W. O clima, segundo a classificação de Köppen (1948), é do tipo Aw e caracteriza-se por uma estação chuvosa entre os meses de outubro/novembro e março/abril, e um período seco entre maio e setembro. O relevo é plano a suave ondulado e, próximo aos córregos tende a ficar mais declivoso.

Foram amostrados 30 pontos de acordo com o método de topossequências em três profundidades 0 - 20, $40-60$ e $80-100 \mathrm{~cm}$, designadas respectivamente de camadas $\mathrm{A}$, B e C. As amostras foram preparadas em laboratório para secagem $\left(45^{\circ} \mathrm{C}\right.$ por 24 horas em estufa) moídas e peneiradas (malha de $2 \mathrm{~mm}$ ). Em seguida foram realizadas as análises granulométrica (Camargo et al., 1986) e químicas para $\mathrm{pH} \mathrm{em} \mathrm{CaCl}_{2}$, teor de matéria orgânica (MO), fósforo, potássio, cálcio, magnésio, alumínio, hidrogênio, CTC, saturação por bases e saturação por alumínio (Raij et al., 1987).

\subsubsection{Obtenção dos dados radiométricos}

Os dados espectrais de cada amostra foram obtidos em laboratório por meio do sensor Infra Red Intelligent Spectroradiometer. A faixa espectral do radiômetro estendese de 450 a $2.500 \mathrm{~nm}$, com uma resolução espectral de $2 \mathrm{~nm}$ entre 450 e $1.000 \mathrm{~nm}$ e 4 $\mathrm{nm}$ entre 1.000 e $2.500 \mathrm{~nm}$. A geometria do sistema foi baseada no posicionamento do sensor a $27 \mathrm{~cm}$ acima da amostra, que foi colocada em placas de petri com $9 \mathrm{~cm}$ de diâmetro e $1,2 \mathrm{~cm}$ de altura. A fonte de iluminação, uma lâmpada halógena de $650 \mathrm{~W}$ 
com refletor parabólico e feixe não-colimado para o plano do alvo, foi posicionado a 61 $\mathrm{cm}$ do alvo em um ângulo zenital de $20^{\circ}$. A energia elétrica foi estabilizada por uma fonte de potência para evitar distúrbios de intensidade na iluminação . O padrão absoluto de referência utilizado foi uma placa espectralon branca com reflectância calibrada em 100 \%. A razão espectral entre o fluxo de radiação refletido pela superfície de referência e a amostra gerou o fator de reflectância bidirecional (Nicodemus et al.,1977).

\subsubsection{Análise estatística}

A análise estatística foi realizada entre os dados de reflectância obtidos em laboratório com os atributos químicos (matéria orgânica, soma de bases, CTC, $\mathrm{V} \%, \mathrm{~m} \%$, $\mathrm{pH}$ em $\mathrm{CaCl}_{2}$, fósforo, potássio, cálcio e magnésio, alumínio e hidrogênio) dos solos. Foram selecionadas para os dados espectrais 22 bandas $(B)$ e 13 alturas $(H)(\mathrm{em} \mathrm{nm})$ : B1: 420-48, B2: 481, B3: 481-596, B4: 596-710, B5: 710-814, B6: 814-975, B7: 9751350, B8: 1350-1417, B9: 1417, B10: 1417-1449, B11: 1449-1793, B12: 1793-1831, B13: 1865-1927, B14: 1927, B15: 1927-2102, B16: 2101-2139, B17: 2139-2206, B18: 2206, B19: 2206-2258, B20: 2258, B21: 2258-2389, B22: 2389-2498; H1: 469-532, H2: 532-768, H3: 768-876, H4: 876-1353, H5: 1353-1411, H6: 1411-1439, H7: 1439-1783, H8: 1860-1923, H9: 1923-2120, H10: 2120-2206, H11: 2206-2258, H12: 2258-2389, H13: 2389-2498, sugeridas por Nanni \& Demattê (2001).

Inicialmente, foi realizada a seleção de variáveis (bandas e alturas) para cada atributo do solo através da análise stepwise. Em seguida, realizou-se o teste de multicolinearidade para eliminação de uma ou mais variáveis que atuavam concomitantemente na estimativa de um mesmo atributo, o que causava uma super estimativa deste atributo. Logo após, gerou-se o modelo estatístico, utilizando-se 60 amostras de terra das camadas $\mathrm{A}$ e $\mathrm{C}$, através de regressão linear múltipla. Estas análises foram realizadas pelo Sistema de Análise Estatística SAS (SAS, 1999).

Posteriormente, valores estimados foram gerados para 41 amostras destinadas para teste. Estes valores foram obtidos apenas para os atributos cujo $\mathrm{R}^{2}$ da equação de regressão múltipla apresentou valores maiores que 0,50 . Em seguida realizou-se teste $t$ 
para verificar a igualdade entre as médias dos valores determinados em análise de laboratório e os estimados por radiometria.

Para o cálculo da necessidade de calagem (NC), utilizou-se o método da saturação por bases, o qual é dado pela seguinte equação:

$$
\mathrm{NC}=\frac{\mathrm{CTC} *\left(\mathrm{~V}_{2}-\mathrm{V}_{1}\right)}{10^{*} \text { PRNT }}
$$

Na qual: CTC: Capacidade de troca catiônica; $\mathrm{V}_{2}$ : Saturação por bases desejada; $\mathrm{V}_{1}$ : Saturação por bases atual; PRNT: Poder reativo de neutralização total do calcário comercial.

Neste trabalho, utilizou-se $\mathrm{V}_{2}$ de $70 \%$ por ser um valor médio requerido por grande parte das culturas e PRNT também de 70\% por ser o valor da maior parte dos cálcarios utilizados no Estado de Minas Gerais.

\subsection{Resultados e Discussão}

\subsubsection{Equações de regressão múltipla}

Os atributos $\mathrm{m} \%, \mathrm{pH}$ em $\mathrm{CaCl}_{2}$, e $\mathrm{Al}$ não obtiveram equações com resultado satisfatório, apresentando coeficientes de determinação em torno de 0,1 (Tabela 1) bem mais baixos do que os verificados por Dunn et al. (2002) com 0,8 para pH e 0,58 para $\mathrm{Al}$; Chang et al. (2001) e Malley et al. (1999) com 0,56 e 0,66 para pH, respectivamente; Nanni \& Demattê (2001) com 0,32 e Fiorio (2002) com 0,68 para $\mathrm{m} \%$. Outro atributo que apresentou valor de $\mathrm{R}^{2}$ menor que 0,5 foi o hidrogênio com 0,42 . É interessante notar que os quatro atributos que apresentaram os menores coeficientes de determinação estão relacionados ( $\mathrm{pH}$ e H, m\% e Al). Estudos anteriores como de Schreier (1977) verificaram correlação positiva para elementos trocáveis como Ca e Mg. Posteriormente, Boluda et al. (1993) confirmaram tais observações. Em ambos os casos as bases trocáveis apresentaram-se como elementos refletivos. Portanto, é de se esperar que na medida em que se aumenta os teores de bases, ocorra aumento da reflectividade o que foi comprovado por Demattê et al. (1998b). Por outro lado, tem-se poucas informações 
da atuação dos elementos relacionados à acidez do solo, como $\mathrm{H}, \mathrm{Al}$ e pH. A falta de resultados justamente para esses elementos indica não haver uma definição lógica sobre seus aumentos e diminuições com a energia refletida.

A equação para $\mathrm{MO}$, no entanto, foi a que apresentou maior valor de $\mathrm{R}^{2} \operatorname{com} 0,92$ (Tabela 1). Tal resultado é melhor do que aqueles encontrados por Fiorio (2002) com 0,29, Demattê \& Garcia (1999a) que obtiveram $\mathrm{R}^{2}$ de 0,45. A matéria orgânica da região dos Cerrados encontra-se numa situação mais estável conforme verificado por Demattê \& Demattê (1993). Essa estabilidade implica em menores variações na sua composição. Sabe-se que a composição como ácidos fúlvicos e húmicos (Henderson et al., 1992) alteram a reflectância. No caso, a estabilidade do material permitiu uma correlação mais adequada entre reflectância e teor de MO.

Para SB, V e CTC, obteve-se valores de $\mathrm{R}^{2}$ de $0,83,0,77$ e 0,88 respectivamente (Tabela 1). Outros autores verificaram valores semelhantes aos aqui observados como Chang et al. (2001) com 0,81 para CTC e 0,75 para SB e Demattê \& Garcia (1999a) que obtiveram 0,71 para CTC e SB. Entretanto, Demattê \& Garcia (1999b) encontraram coeficientes menores que 0,5 para os mesmos três atributos. A CTC potencial $(\mathrm{pH} 7,0)$ é um atributo determinado pela soma das bases trocáveis, $\mathrm{H}$ e Al. Como demonstrado, muitos dos trabalhos de literatura vêm obtendo correlações razoáveis com a energia refletida. Portanto, a energia que incide sobre esses elementos que compõem a CTC, reflete a capacidade de retenção. $\mathrm{Na}$ área em questão, a CTC foi baixa para a maioria das amostras de terra (na faixa de $42 \mathrm{mmol}_{\mathrm{c}} \mathrm{dm}^{-3}$ ). Ou seja, mesmo com dados sem alta variação, a correlação foi razoável, indicando que o que compõe a CTC está influindo diretamente na energia refletida.

As bases trocáveis (P, K, Ca e $\mathrm{Mg}$ ) mostraram valores de $\mathrm{R}^{2}$ entre 0,67 e 0,84 (Tabela 1) o que foi considerado satisfatório. Estes resultados corroboram aqueles obtidos por Janik et al. (1998) e Thomasson et al.(2001). Entretanto, Dematê \& Garcia (1999b) obtiveram valores menores que 0,4 para os quatro elementos enquanto Malley et al. (1999) apresentaram $\mathrm{R}^{2}$ maiores que 0,9 também para estes nutrientes. As diferenças observadas entre os resultados obtidos neste trabalho e os demais citados na literatura pode estar relacionado aos equipamentos utilizados que apresentam resoluções 
diferentes, com a seleção das melhores bandas para a elaboração dos modelos, como observado por Huete \& Escadafal (1991).

Além disso, a alternância de resultados mais ou menos confiáveis indica estar relacionado com os locais e regiões de amostragem. Enquanto Demattê \& Garcia (1999b) correlacionaram elementos químicos com reflectância em amostras de terra de regiões distintas do Estado do Paraná, perfazendo até 25.620 ha com um total de 45 amostras, Thomasson et al. (2001) por sua vez avaliaram áreas de aproximadamente 273 ha com 724 amostras. Nanni \& Demattê (2001) e Fiorio (2002) seguiram a mesma linha estudando áreas com 280 e 500 ha respectivamente, e alta densidade de amostragem. Ou seja, quimicamente, tudo indica que devam ser avaliados e elaborados modelos para áreas menores.

Com o intuito de verificar a possibilidade de utilização destas equações na predição dos atributos químicos dos solos, 41 amostras não utilizadas para gerar o modelo foram usadas para teste. Os atributos testados foram aqueles cujo $\mathrm{R}^{2}$ foi maior que 0,5 . Desta forma, obteve-se os valores estimados (VE) para as 30 amostras, os quais foram comparados com os valores determinados em laboratório de análise de solo (VD) através do teste $t$ (Tabela 2).

Verifica-se que os resultados obtidos pelas equações na predição dos atributos químicos, representados pela média das 41 amostras, apresentaram-se estatisticamente iguais a média dos valores determinados em laboratório para as mesmas 41 amostras (Tabela 2). Tais resultados levam a crer que não ocorrem diferenças entre as análises feitas por sensor e por laboratório. Resultado semelhante foi obtido por Fiorio (2002) para MO, V, SB e CTC que também não apresentaram diferenças significativas entre os valores estimados e determinados.

Os dados espectrais entre 450 e $2500 \mathrm{~nm}$ de uma amostra de terra, referem-se ao resultado da interação entre a energia eletromagnética refletida com os inúmeros fatores da amostra. Alguns destes fatores têm uma relação mais forte com a energia incidente. Ë o caso dos óxidos de ferro, matéria orgânica, tamanho de partículas e a mineralogia, devidamente comprovado em literatura. Por outro lado, sabe-se que a energia incidente também interage com outros elementos, como os que estão na solução do solo. A relação 
entre reflectância e elementos da solução, como $\mathrm{Ca}, \mathrm{Mg}, \mathrm{K}$ e $\mathrm{P}$ foram pouco estudados, justamente devido aos estudos anteriores terem dado maior ênfase aos elementos considerados como mais interferentes.

Com o advento da Agricultura de Precisão e a necessidade de otimizar e racionalizar custos das amostras de terra, novos trabalhos em sensoriamento remoto vêm sendo realizados, agora porém dando ênfase à química do solo. Foi assim, que Demattê et al. (1998b) através de ensaios em laboratório verificou que o cálcio é um elemento refletivo, que pode alterar a intensidade de reflectância da amostra de terra, através da calagem, por exemplo. Posteriormente, Demattê et al. (2001b) determinaram que a aplicação de resíduos agro-industriais líquidos advindos da cana de açúcar como vinhaça, promoveram alterações químicas nas amostras de terra (aumento de $\mathrm{K}$ e $\mathrm{Ca}$, por exemplo), que por sua vez foram observadas pala reflectância. No caso, os autores verificaram alteração na intensidade de reflectância. Estes casos mostraram a importância dos elementos da solução do solo na energia refletida. Por outro lado, ainda ficaria a questão: "o quanto desta influência pode ser detectada; ou ainda, qual a porcentagem de contribuição desses elementos na energia refletida, uma vez que os outros elementos (como ferro e MO) podem mascará-los ?"

Com base nestas questões, trabalhos como os de Thomasson et al. (2001) e Dunn et al. (2002) indicaram que a energia eletromagnética, quando estudada de maneira pormenorizada pelas bandas, pode detectar as variações dos elementos trocáveis. $\mathrm{O}$ presente trabalho, conforme resultados das Tabelas 1 e 2 ratificam os resultados destes trabalhos, indicando que o espectro eletromagnético está sendo também influenciado por estes elementos, e portanto, são detectáveis em função da metodologia de avaliação.

\subsubsection{Necessidade de calagem}

A acidez dos solos é reconhecidamente um dos principais fatores da baixa produtividade dos solos brasileiros, que contêm teores tóxicos de alumínio e, às vezes manganês além de teores baixos de cálcio e magnésio e da absorção dificultada de outros nutrientes (Raij, 1991). Desta forma, a calagem é prática fundamental para a 
melhoria do ambiente radicular das plantas pela neutralização do alumínio e manganês, fornecimento de cálcio e magnésio como nutrientes e aumento da disponibilidade de cargas, e de outros nutrientes como o fósforo.

Um dos métodos utilizados para a determinação da necessidade de calagem é o critério baseado na elevação da saturação por bases. Este método preconiza a elevação da saturação por bases a valores pré estabelecidos para cada cultura. Verificou-se que os valores de V\% e CTC são iguais estatisticamente (Tabela 2) desta forma, realizou-se a comparação entre a necessidade de calagem (NC) usando os resultados analíticos e os teores estimados pela equação de regressão. A figura 1 mostra que houve correlação entre a NC determinada e a NC estimada com um $\mathrm{R}^{2}$ de 0,62 , ou seja, os dados radiométricos conseguiram determinar a quantidade de calcário a ser aplicada na área. $\mathrm{O}$ presente resultado concorda com autores como Janik et al. (1998). Estes autores obtiveram uma excelente predição da $\mathrm{NC}$ com $\mathrm{R}^{2}$ de 0,85 quando comparou a necessidade medida e a predita na faixa do infravermelho médio.

A necessidade de calagem não está somente ligada com o $\mathrm{pH}$, mas também com a sua capacidade tampão e a sua CTC. Solos mais tamponados (mais argilosos) necessitam de mais cálcario para aumentar o $\mathrm{pH}$ do que os menos tamponados (mais arenosos). A capacidade tampão está relacionada diretamente com os teores de argila, matéria orgânica e tipo de argila (Alvarez V. \& Ribeiro, 1999).

A aplicação de calcário, além das alterações químicas já citadas, promove o aumento nos teores de cálcio, que por sua vez aumentam a reflectividade do solo, conforme verificado por correlações positivas observadas por Schreier (1977) e descrições mais detalhadas em Demattê et al. (1998b). Ou seja, verifica-se três tipos de situação que convergem para a mesma conclusão. Na primeira, autores (Demattê et al., 1998b) demonstram que as doses de calcário alteram os dados espectrais. Num segundo caso, são verificadas correlações positivas entre V\% e refletância (Nanni, 2000; Fiorio, 2002). Na última situação, fez-se o sentido inverso, verificando pela radiometria a possibilidade de quantificar a NC, obtendo-se resultados razoáveis, conforme apresentado na Figura 1 em concordância com Janik et al. (1998). 


\subsection{Conclusões}

1- É possível estimar matéria orgânica, CTC, V, SB, P, K, Ca e Mg a partir da resposta espectral de solos para a referida região e modelos específicos.

2- A metodologia aqui utilizada tem potencial para auxiliar os métodos convencionais de análise de solo, assim como ajudar na determinação da necessidade de calagem para utilização na Agricultura de Precisão. 


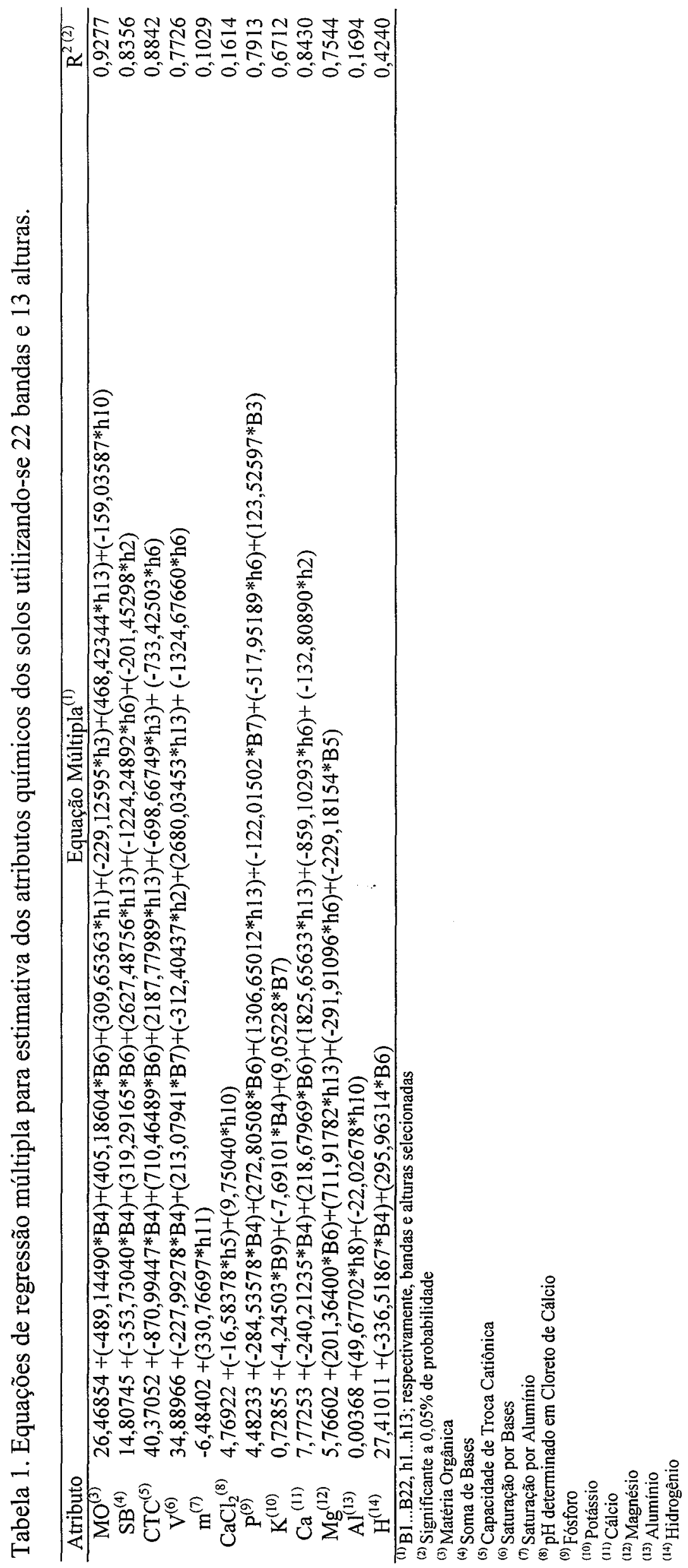




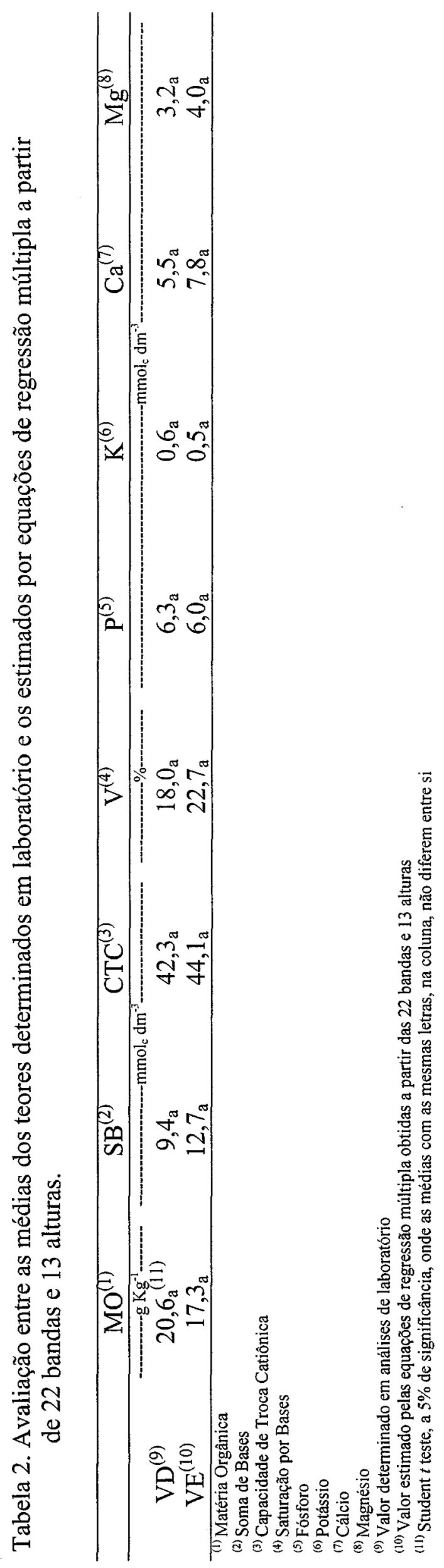




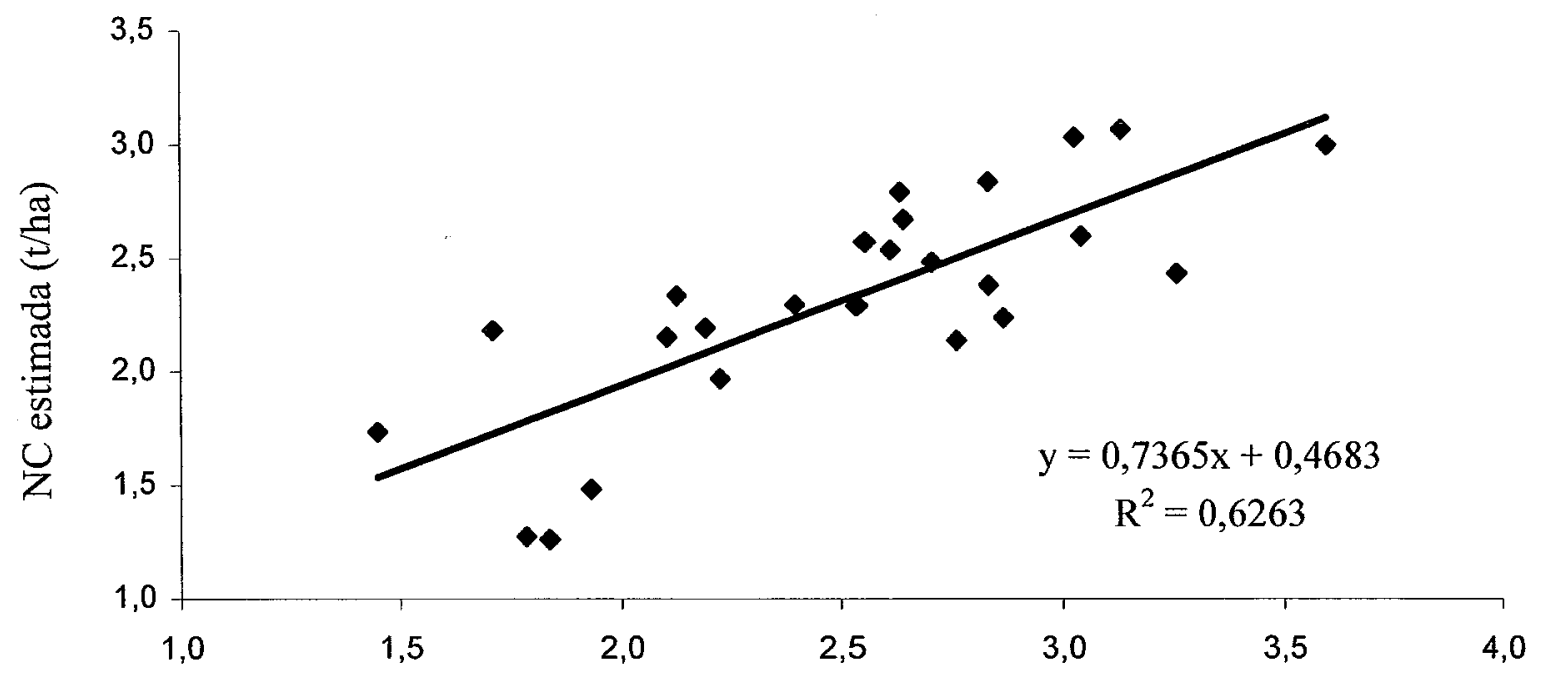

NC determinada ( $\mathrm{t} / \mathrm{ha}$ )

Figura 1 - Gráfico de correlação entre a necessidade de calagem (NC) determinada a partir dos resultados da análise de laboratório e da estimada através dos dados radiométricos. 


\section{CONCLUSÕES GERAIS}

1- Os dados radiométricos permitiram identificar a composição mineralógica dos solos com relação à presença de óxidos de ferro, minerais 2:1, caulinita e gibbsita.

2- A determinação de teores de atributos do solo como areia, silte, argila, $\mathrm{SiO}_{2}, \mathrm{Al}_{2} \mathrm{O}_{3}$, $\mathrm{TiO}_{2}$ e $\mathrm{Fe}_{2} \mathrm{O}_{3}$ pode ser realizada pela energia eletromagnética refletida utilizando-se a metodologia proposta neste trabalho.

3- Foi possível estimar matéria orgânica, CTC, V, SB, P, K, Ca e Mg a partir da resposta espectral de solos para a referida região e modelo específico. Os dados de radiometria permitiram estimar a necessidade de calagem, relacionando-se, portanto, com o manejo químico. 


\section{REFERÊNCIAS BIBLIOGRÁFICAS}

ALVAREZ V., V.H.; RIBEIRO, A.C. Calagem. In: RIBEIRO, A.C.; GUIMARÃES, P.T.G.; ALVAREZ V., V.H. (Ed.). Recomendações para o uso de corretivos e fertilizantes em Minas Gerais. Viçosa: CFSEMG, 1999. p. 43-60.

BARET, F.; JACQUEMOUND, S.; HANOCQ, J. F. The soil line concept in remote sensing. Remote Sensing of Environment, v.7, n.l, p.1-18, 1993.

BARRÓN, V.; DE MELLO, J.W.V.; TORRENT, J. Caracterização de óxidos de ferro em solos por espectroscopia de reflectância difusa. In: NOVAIS, R.F.; ALVAREZ V., V.H.; SCHAEFER, C.E.G.R. (Ed.) Tópicos em Ciência do Solo. Viçosa: SBCS, 2000. v.1, p. 139-162.

BAUMGARDNER, M. F.; KRISTOF, S. J.; JOHANNSEN, C. J.; ZACHARY, A. L. Effects of organic matter on the multiespectral properties of soils. Proceedings of the Indiana Academy of Science, v.79, p.413-422, 1970.

BEN-DOR, E. Quantitative remote sensing of soil properties. Advances in Agronomy, v.75, p.173-243, 2002.

BEN-DOR, E.; BANIN, A. Near-Infrared analysis (NIRA) as a rapid method to simultaneously evaluate several soil properties. Soil Science Society of America Journal, v. 59, p.364-372, 1995a.

BEN-DOR, E.; BANIN, A. Near-Infrared analysis as a simultaneously method to evaluate spectral featureless constituents in soils. Soil Science, v.159, p.259-269, 1995b.

BEN-DOR, E; IRONS, J.R.; EPEMA, G.F. Soil reflectance. In: RENCZ, A. N. (Ed.). Remote sensing for earth sciences: manual of remote sensing. 3. ed. Danvers: John Wiley, 1999. v.3, p.111-188. 
BEN-GERA, I.; NORRIS, K. Determination of moisture content in soybeans by direct spetrophotometry. Israel Journal of Agricultural Research, v.18, p.124-132, 1968.

BOLUDA, R.; COLOMER, J.C.; MORELL, C.; SÁNCHEZ, J. Estudio de las curvas de reflectividad y su relacion con las propriedades de los suelos en zona semiarida. In: CONGRESSO IBEROAMERICANO DE LA CIENCIA DEL SUELO, Salamanca, 1993. Anales, Espanha: Mundi-prensa, 1993, p. 1-8

BORGELT, S.C.; SEARCY, S.W.; STOUT, B.A.; MULLA, D.J. Spatially variable liming rates: a method for determination. Transaction of the ASAE, v.37, n.5, p.1499-1507, 1994.

BOWERS, S.A.; HANKS, R.J. Reflection of radiant energy from soils. Soil Science, v.100, n.2, p.130-138, 1965.

BULLOK, P.; BRISCO, B.; HIROSE, T. Remote sensing for improving crop management. In: INTERNATIONAL CONFERENCE ON GEOSPATIAL INFORMATION IN AGRICULTURE AND FORESTRY. Lake Buena Vista, 2000. Proceedings, Florida: Erim, 2000.p. II-487 - 494.

CAMARGO, A. O. de; A. C. MONIZ; J. A. JORGE; J. M. VALADARES. Métodos de análise química, mineralógica e física de solos do IAC. Campinas: Instituto Agronômico, 1986. 94 p. (IAC. Boletim Técnico, 106).

CHABRILLAT, S.; GOETZ, A.F.H.; KROSLEY, L.; OLSEN, H.W. Use of hyperspectral images in the identification and mapping of expansive clays soils and the role of spatial resolution. Remote Sensing of Environment, v.82, p.431-445, 2002.

CHANG, C.W.; LAIRD, D.A.; MAUSBACH, M.J.; HURBURGH JUNIOR, C.R. Nearinfrared reflectance spectroscopy - principal components regression analyses of soil properties. Soil Science Society of America Journal, v.65, p. 480-490, 2001.

CLARK, R.N.; KING, T.V.V.; KLEIWA, M.; SWAYZE, G.A.; VERGO, N. High spectral resolution reflectance spectroscopy of minerals. Journal of Geophysical Research, v. 95, p. 12653-12680, 1990. 
COLEMAN, T. L; MONTGOMERY, O. L. Assessment of spectral characteristics for differentiating among soil categories in the southeastern united States. Photogrammetric Engineering \& Remote Sensing, v.52, p.1659-1663, 1990.

COLEMAN, T. L.; AGBU, P. A.; MONTGOMERY, O. L.; GAO, T.; PRASAD, S. Spectral band selection for quantifying selected properties in highly weathered soils. Soil Science, v.151, n.5, p.355-361, 1991.

CONDIT, H. R. The spectral reflectance of american soils. Photogrammetric Engineering, v.36, n.9, p.955-968, 1970.

CORNELL, R.M.; SCHWERTMANN, U. The iron oxides: structure, properties, reactions, occurrence and uses. Weinheim:VCH, 1996, 573p.

COURAULT, D.; GIRARD, M.C. Relationships between the soil composition and their spectral signature. In: SYMPOSIUM OF THE WORKING GROUP REMOTE SENSING, 5., Budapest, 1988. Proceedings. Budapest: ISSS, 1988. p. 178-185.

DEMATTE, J.A.M. Relações entre dados espectrais e características físicas, químicas e mineralógicas de solos desenvolvidos de rochas eruptivas. Piracicaba, 1995. 265p. Tese (Doutorado) - Escola Superior de Agricultura “Luiz de Queiroz”, Universidade de São Paulo.

DEMATTÊ, J. A. M. Reflectância espectral de solos. Piracicaba, 1999. 452p. Tese (Livre Docência) - Escola Superior de Agricultura "Luiz de Queiroz", Universidade de São Paulo.

DEMATTÊ, J.A.M. Characterization and discrimination of soils by their electromagnetic energy. Pesquisa Agropecuária Brasileira, v.37, p. 1445-1458, 2002

DEMATTÊ, J.A.M.; GARCIA, G.J. Alteration of soil properties through a weathering sequence as evaluated by spectral reflectance. Soil Science Society of America Journal, v.63, n.2, p. 327-342, 1999a.

DEMATTÊ, J.A.M.; GARCIA, G.J. Avaliação de atributos de Latossolo Bruno e de Terra Bruna Estruturada da região de Guarapuava, Paraná, por meio de sua energia refletida Revista Brasileira de Ciência do Solo, v.23, p.343-355, 1999 b. 
DEMATTÊ, J.A.M.; CAMPOS, R.C.; ALVES, M.C. Avaliação espectral de solos desenvolvidos em uma topossequência de diabásio e folhelho da região de Piracicaba, SP. Pesquisa Agropecuária Brasileira, v.35, p. 2447-2460, 2000.

DEMATTE, J. A. M.; GARCIA, G. J.; PROCHNOW, L. I. Variações induzidas de atributos químicos e sua influência na reflectância espectral de três solos do Estado do Paraná. Revista Brasileira de Ciência do Solo, v.22, p.479-490, 1998b.

DEMATTÊ, J. A.M.; PEREIRA, H.S.; NANNI, M. R. Chemical alterations of a soil promoted by the application of agriculture products as assessed by spectral reflectance (compact disc). In: INTERNATIONAL CONFERENCE OF GEOSPATIAL INFORMATION IN AGRICULTURE AND FORESTRY, Denver, 2001. Proceedings, Colorado: Veridian, $2001 \mathrm{~b}$.

DEMATTÊ, J.A.M.; COOPER, M.; FIORIO, P. R.; MAULE. R. Soil characterization and discrimination on a topossequence over diabase through their reflected energy (Compact disc). In: WORLD CONGRESS ON SOIL SCIENCE, 16., Montpellier, 1998. Montpellier: AFES, 1998a .

DEMATTÊ, J.A.M.; DEMATTÊ, J.L.I.; CAMARGO, W.P.; FIORIO, P.R.; NANNI, M.R. Remote sensing in the recognition and mapping of tropical soils developed on topographic sequences. Mapping Science and Remote Sensing, v. 38, p. 79-102, 2001 .

DEMATÊ, J.L.I.; DEMATTÊ, J.A.M. Comparações entre as propriedades químicas de solos das regiões da floresta amazônica e do cerrado do Brasil Central. Scientia Agricola, v.50, p.272-286, 1993.

DUNN, B.W.; BEECHER, H.G.; BATTEN, G.D.; CIAVARELLA, S. The potential of near-infrared reflectance spectroscopy for soil analysis - a case study from the Riverine Plain of south-eastern Australia. Australian Journal of Experimental Agriculture, v. 42, p. 607-614, 2002.

EMPRESA BRASILEIRA DE PESQUISA AGROPECUÁRIA. Centro Nacional de Pesquisa de Solos. Sistema brasileiro de classificação de solos. Brasília: Serviço de Produção, 1999. 412 p. 
EPIPHANIO, J.C.N.; FORMAGGIO, A.R.; VALERIANO, M.; OLIVEIRA, J.B. Comportamento espectral de solos do Estado de São Paulo. São José dos Campos: INPE, 1992. 131p.

FIORIO, P.R. Dados radiométricos obtidos nos níveis terrestre e orbital na avaliação de solos. Piracicaba, 2002. 198p. Tese (Doutorado) - Escola Superior de Agricultura "Luiz de Queiroz", Universidade de São Paulo.

FORMAGGIO, A.R.; EPIPHANIO, J.C.N.; VALERIANO, M.M.; OLIVEIRA, J.B. Comportamento spectral $(450-2450 \mathrm{~nm})$ de solos tropicais de São Paulo. Revista Brasileira de Ciência do Solo, v. 20, p. 467-474, 1996.

FRAISSE, C.W. Agricultura de precisão: a tecnologia de GIS/GPS chega as fazendas. http:www.fatorgis.com.br (10 ago. 1998).

FROST, R.L.; LOCOS, O.B.; RUAN, H.; KLOPROGGE, J.T. Near-infrared and midinfrared spectroscopic study of sepiolites and palygorskites. Vibrational Spectroscopy, v.27, p.1-13, 2001.

GALVÃO, L. S.; VITORELLO, I. Variability of laboratory measured soil lines of soil from southeastern Brazil. Remote Sensing of Environment, v.6, n.2, p.166-181, 1998.

GALVÃO, L. S.; VITORELLO, I.; FORMAGGIO, A.R. Relationships of spectral reflectance and color among surface and subsurface horizons of tropical soil profiles. Remote Sensing of Environment, New York, v.61, p. 24-33, 1997.

GROVE, C. I.; HOOK, S. J.; TAYLOR, E. D. Laboratory reflectance spectra of 160 minerais, 0.4 to 2.5 micrometers. Passadena: National Aeronautics and Space Administration, 1992.355p.

HAUFF, P. L.; KRAUSE, F. A.; TIURY, M. Spectral identification and characterization of kaolinite/smectite clays in weathering environments. In: AUSTRALIAN REMOTE SENSING CONFERENCE, 5., Perth, 1990. Proceedings. Perth: Remote Sensing and Photogrammetry Association of Australasia, 1990. p.898-905. 
HENDERSON, T.L.; BAUMGARDNER, M.F.; FRANZMEIER, D.E.; STOTT, D.E.; COSTER, D.C. High dimensional reflectance analysis of soil organic matter. Soil Science Society of America Journal, v. 56, p. 865-872, 1992.

HUETE, A. R. Soil influences in remotely sensed vegetation-canopy spectra. In: ASRAR, G. (Ed.) Theory and application of optical remote sensing. New York: Wiley Interscience, 1989. p.107-141.

HUETE, A.R.; ESCADAFAL, R. Assessment of biophisical soil properties through spectral decomposition techniques. Remote Sensing of Environment, v.35, p.149159,1991

HUNT, G.R.; SALISBURY, G.W. Visible and near infrared spectra of minerals and rocks I - Silicate minerals. Modern Geology, v.2, p.283-300, 1970.

HUNT, G.R.; SALISBURY, G.W.; LENHOFF,C.J. Visible and near infrared spectra of minerals and rocks III - Oxides and hydroxides. Modern Geology, v.2, p.195-205, 1971.

JANIK, L.J.; MERRY, R.H.; SKJEMSTAD, J.O. Can mid infrared diffuse reflectance analysis replace soil extractions? Australian Journal of Experimental Agriculture, v. 38, p. 681-696, 1998.

KÄMPF, N.; CURI, N. Óxidos de ferro: indicadores de ambientes pedogênicos e geoquímicos. In: NOVAIS, R.F.; ALVAREZ V., V.H.; SCHAEFER, C.E.G.R. (Ed.). Tópicos em ciência do solo. Viçosa: SBCS, 2000. v.1, p. 107-138

KÄMPF, N.; SCHWERTMANN, U. Relações entre óxidos de ferro e a cor em solos cauliníticos do Rio Grande do Sul. Revista Brasileira de Ciência do Solo, v.7, p. 27-31, 1983.

KOEPPEN, W. Climatologia. México: Ed. Fondo de Cultura Económica, 1948. 130p.

KOSMAS, C.S.; CURI, N.; BRYANT, R.B.; FRANZMEIER, D.P. Characterization of iron oxides minerals by second-derivative visible spectroscopy. Soil Science Society of America Journal, v.48, p. 401-405, 1984. 
KRUSE, F. A.; TIERY, M.; HAUFF, P. L. Spectral identification $(1,2-2,5 \mathrm{~nm})$ and characterization of Paris Basin kaolinite/smectite clays using a field spectrometer. In: INTERNATIONAL COLLOQUIUM - PHYSICAL MEASUREMENTS AND SIGNATURES IN REMOTE SENSING, 5., Courchevel, 1991. Proceedings. Courchevel: ESA, 1991.p.181-184.

LEMOS, R.C. de; SANTOS, R.D. dos. Manual de descrição e coleta de solo no campo. 3. ed. Campinas: Sociedade Brasileira de Ciência do Solo, 1996. 84p.

LEONE, A.P.; SOMMER, S. Multivariate analysis of laboratory spectra for the assessment of soil development and soil degradation in the southern Apennines (Italy). Remote Sensing of Environment, v. 72, p.346-359, 2000.

LILLESAND, T.M.; KIEFER, R.W. Remote sensing and image interpretation. New York: John Wiley, 2000. 724 p.

LOBELL, D.B.; ASNER, G.P. Mositure effects on soil reflectance. Soil Science Society of America Journal, v. 66, p.722-727, 2002.

MADEIRA NETTO, J. S. Étude quantitative des relations constituants minéralogiques réflectance diffuse des latosols brésiliens: applications à l'utilization pédologique des donées satellitaires TM (région de Brasilia). Paris, 1993. 236p. Thèse (Docteur) - Institut Francais de la Recherche Scientifique pour le Developpement Scientifique en Cooperation .

MADEIRA NETTO, J. S. Spectral reflectance properties of soils. Photo Interprétation, v.34, p. 59-70, 1996.

MALLEY , D.F.; YESMIN, L.; WRAY, D.; EDWARDS, S. Application of nearinfrared spectroscopy in analysis of soil mineral nutrients. Communications in Soil Science and Plant Analysis, v. 30, n. 7-8, p. 999-1012, 1999.

MAPA, R.B.; KUMARAGAMAGE, D. Variability of soil properties in a tropical Alfisol used for shifting cultivation. Soil Technology, v.9, p.187-197, 1996.

MATHEWS, H.L.; CONNINGHAM, R.L.; PETERSEN, G.W. Spectral reflectance of selected Pennsylvania soils. Soil Science Society of America Proceedings, v. 37, p. 421-424, 1973. 
MORAES, E. C. Comportamento espectral. In: SIMPÓSIO BRASILEIRO DE SENSORIAMENTO REMOTO, 8., Santos, 1996. Anais. São José dos Campos: INPE, 1996. v. 1, p.1-26.

MORRIS, R.V.; LAUER JUNIOR, H.V.; LAWSON, C.A.; GIBSON JUNIOR, E.K.; NACE, G.A.; STEWART, C. Spectral and other physicochemical properties of submicron powders of hematite $\left(\mathrm{Fe}_{2} \mathrm{O}_{3}\right)$, maghemite $\left(\mathrm{Fe}_{2} \mathrm{O}_{3}\right)$, magnetite $\left(\mathrm{Fe}_{3} \mathrm{O}_{4}\right)$, goethite (FeOOH) and lepidocrocite (FeOOH). Journal of Geophysical Research, v.90, p. $3126-3144,1985$.

NANNI, M. R. Dados radiométricos obtidos em laboratório e no nível orbital na caracterização e mapeamento de solos. Piracicaba, 2000. 366p. Tese (Doutorado) Escola Superior de Agricultura "Luiz de Queiroz", Universidade de São Paulo.

NANNI, M. R.; DEMATTÊ, J. A. M. Is it possible estimate physical-chemical soil attributes by using laboratory and orbital sensors (compact disc). In: INTERNATIONAL CONFERENCE OF GEOSPATIAL INFORMATION IN AGRICULTURE AND FORESTRY, Denver, 2001. Proceedings, Colorado: Veridian, 2001.

NICODEMUS, F.E.; RICHMOND, J.C.; HSIA, J.J.; GINSBERG, I.W.; LIMPERIS, T. Geometrical considerations and nomenclature for reflectance. Washington: U.S. Departmente of Commerce, 1977. 52 p. (NBS Monograph 160).

OBUKHOV, A. I.; ORLOV, O. S. Spectral reflectance of major soil groups and possibility of using diffuse reflections in soil investigations. Soviet Soil Science, v.1, p.174-184, 1964.

RAIJ, B. van. Fertilidade do solo e adubação. Piracicaba: Editora Agronômica Ceres; Potafos, 1991. 343p.

RAIJ, B. van.; CANTARELlA, H.; QUAGGIO, J.A.; FURLANI, A.M.C. Recomendações de adubação e calagem para o Estado de São Paulo, 2 ed. Campinas: Instituto Agronômico; Fundação IAC, 1996. 285 p. (Boletim Técnico, 100). 
RAIJ, B. van.; QUAGGIO, J.A.; CANTARELLA, H; FERREIRA, M. E.; LOPES, A. S.; BATAGLIA, C.O. Análise química do solo para fins de fertilidade. Campinas: Fundação Cargill, 1987.170 p.

SABINS JUNIOR., F. F. Remote sensing : principles and interpretations. San Francisco : W. H. Freeman, 1987. 449 p.

SAS INSTITUTE. SAS, software: user's guide, version 8.2. Cary, 1999. 219p.

SAVITZKY, A.; GOLAY, M.J.E. Smoothing and differentiation of data by simplified least square procedures. Analytical Chemistry, v.36, p.1627-1639, 1964

SCHEINOST, A.C.; SCHWERTMANN, U. Color identification of iron oxides and hydroxysulfates: use and limitations. Soil Science Society of America Journal, v.63, p. 1463-1471, 1999.

SCHEINOST, A.C.; CHAVERNAS, A.; BARRÓN, V.; TORRENTE, J. Use and limitations of second-derivative diffuse reflectance spectroscopy in the visible to nearinfrared range to identify and quantify Fe oxides minerals in soils. Clays and Clays Minerals, v.46, p.528-536, 1998.

SCHREIER, H. Quantitative predictions of chemical soil conditions from multi-spectral airbome, ground and laboratory measurements. In: CANADIAN SYMPOSIUM ON REMOTE SENSING, 4. Ottawa, 1977. Proceedings. Ottawa: Canadian Aeronautics and Space Institute, 1977. p.106-112.

SHERMAN, D.M.; WAITE, T.D. Electronic spectra of $\mathrm{Fe}^{3+}$ oxides hydroxides in the near IR to near UV. American Mineralogist, v.70, p. 1262-1269, 1985.

STARK, E.; LUCHTER, K.; MARGOSHES, M. Near-infrared analysis (NIRA): A technology for quantitative and qualitative analysis. Applied Spectroscopy Reviews, v.22, n.4, p.335-399, 1986.

STEFFEN, C. Conviris: software para tratamento de dados espectrais obtidos em laboratório. São José dos Campos: INPE, 1997.

STONER, E. R.; BAUMGARDNER, M. F. Characteristics variations in reflectance of surface soils. Soil Science Society of America Journal, v.45, n.6, p.1161-1165, 1981. 
STONER, E. R.; BAUMGARDNER, M.F.; WEISMILLER, R.A.; BIEHL, L.L.; ROBINSON, B. F. Extension of laboratory measured soil spectra to field conditions. Soil Science Society of America Journal, v.44, p. 572-574, 1980.

STREUS, R.G. F.; WOOD, B. F. Diffuse reflectance spectra and optical properties of some iron and titanium oxides and oxyhydroxides. Mineralogical Magazine, v.43, p.347-354, 1979.

THOMASSON, J.A.; SUI, R.; COX, M.S.; AL-RAJEHY, A. Soil reflectance sensing for determining soil properties in precision agriculture. Transactions of the ASAE, v.44, n.6, p.1445-1453, 2001.

VINOGRADOV. B.V. Remote sensing of the humus content of soils. Soviet Soil Science, v.13, p.103-13, 1981. 